\title{
Sox14 Is Required for a Specific Subset of Cerebello-Olivary Projections
}

\author{
Hong-Ting Prekop, ${ }^{1,2}$ Anna Kroiss, ${ }^{1}$ Victoria Rook, ${ }^{2}$ Laskaro Zagoraiou, ${ }^{3,4}$ Thomas M. Jessell, ${ }^{4}$ Cathy Fernandes, ${ }^{5}$ \\ Alessio Delogu, ${ }^{1}$ and Richard J.T. Wingate ${ }^{2}$ \\ ${ }^{1}$ Department of Basic and Clinical Neuroscience, Institute of Psychiatry, Psychology and Neuroscience, King's College London, London, SE5 9NU, United \\ Kingdom, ${ }^{2} \mathrm{MRC}$ Centre for Neurodevelopmental Disorders, Institute of Psychiatry, Psychology and Neuroscience, King's College London, London SE1 1UL, \\ United Kingdom, ${ }^{3}$ Biomedical Research Foundation Academy of Athens, 11527, Athens, Greece, ${ }^{4}$ Department of Neuroscience, Columbia University, New \\ York, 10027, New York, and ${ }^{5}$ Centre for Social, Genetic and Developmental Psychiatry, Institute of Psychiatry, Psychology and Neuroscience, King's College \\ London, London, SE5 8AF, United Kingdom
}

We identify Sox14 as an exclusive marker of inhibitory projection neurons in the lateral and interposed, but not the medial, cerebellar nuclei. Sox $14^{+}$neurons make up $\sim 80 \%$ of $\mathrm{Gadl}^{+}$neurons in these nuclei and are indistinguishable by soma size from other inhibitory neurons. All Sox $14^{+}$neurons of the lateral and interposed cerebellar nuclei are generated at approximately E10/10.5 and extend longrange, predominantly contralateral projections to the inferior olive. A small Sox $14^{+}$population in the adjacent vestibular nucleus "Y" sends an ipsilateral projection to the oculomotor nucleus. Cerebellar Sox $14^{+}$and glutamatergic projection neurons assemble in nonoverlapping populations at the nuclear transition zone, and their integration into a coherent nucleus depends on Sox14 function. Targeted ablation of Sox $14^{+}$cells by conditional viral expression of diphtheria toxin leads to significantly impaired motor learning. Contrary to expectations, associative learning is unaffected by unilateral Sox $14^{+}$neuron elimination in the interposed and lateral nuclei.

Key words: axon; cerebellum; GABA; genetic model; inferior olive; motor learning

\section{Significance Statement}

The cerebellar nuclei are central to cerebellar function, yet how they modulate and process cerebellar inputs and outputs is still primarily unknown. Our study gives a direct insight into how nucleo-olivary projection neurons are generated, their projections, and their function in an intact behaving mouse. These neurons play a critical conceptual role in all models of cerebellar function, and this study represents the first specific analysis of their molecular identity and function and offers a powerful model for future investigation of cerebellar function in motor control and learning.

\section{Introduction}

The cerebellum is characterized by a remarkably uniform neural structure that executes a repertoire of adaptive neural functions. Its ability to modulate output in a flexible and predictive manner relies on its position within a series of nested, re-entrant loops converging on the modulation of cerebellar nuclei output by in-

Received June 8, 2018; revised Sept. 2, 2018; accepted Sept. 4, 2018.

Author contributions: H.-T.P., A.D., and R.J.T.W. designed research; H.-T.P., A.K., V.R., C.F., and A.D. performed research; H.-T.P., L.Z., and T.M.J. contributed unpublished reagents/analytic tools; H.-T.P. and V.R. analyzed data; H.-T.P. and R.J.T.W. wrote the paper.

This work was supported by Biotechnology and Biological Sciences Research Council Grant BB/L020068/1 to A.D. and a National Institute for Health Research (NIHR) Maudsley Biomedical Research Centre PhD studentship to H.-T.P. We thank Noldus (Wageningen, The Netherlands) for the loan of an Erasmus ladder for this study. We are indebted to Prof. Chris De Zeeuw for discussion of our results. The views expressed are those of the authors and not necessarily those of the National Health Service, the NIHR, or the Department of Health and Social Care.

Correspondence should be addressed to either of the following: Dr. Alessio Delogu, Department of Basic and Clinical Neuroscience, IOPPN, King's College London, 125 Coldharbour Lane, London SE5 9NU, UK, E-mail: Alessio.delogu@kcl.ac.uk; or Dr. Richard J.T. Wingate, MRCCentre for Neurodevelopmental Disorders, 4th Floor New Hunts House, Guy's Campus King's College London, London SE1 1UL, UK, E-mail: Richard.wingate@kcl.ac.uk. hibitory Purkinje cells. One key loop involves the inferior olive, whose climbing fiber output can profoundly influence the activity of Purkinje cells and hence the activity of excitatory cerebellar nuclear efferents. In turn, the cerebellar output nuclei have both excitatory and inhibitory efferents, and it is the descending, longrange inhibitory axons that modulate the output of the inferior olive. This cerebello-nuclear-olivo circuit comprises parallel loops passing via the lateral, interposed, and medial nuclei, which are then further subdivided into discrete functional modules (Cerminara and Apps, 2011).

The nucleo-olivary pathway has been implicated in altering climbing fiber activity (Sears and Steinmetz, 1991; Hesslow and Ivarsson, 1996; Lang et al., 1996; Bengtsson et al., 2004; Lefler et al., 2014; Najac and Raman, 2015), at least partly through modulating the gap junction connectivity within inferior olive sub- 
populations (Kistler et al., 2002; Van Der Giessen et al., 2008). This has been proposed to modulate both synchronous clustering of activity in the inferior olive, thought to be integral for motor timing (Lang et al., 1996; Leznik et al., 2002; Best and Regehr, 2009; Llinás, 2011, 2013), and a more selective weakening of specific olivary outputs during motor learning (Schweighofer et al., 2013) or associative learning (Medina et al., 2002; De Zeeuw et al., 2003; Bengtsson et al., 2007) tasks. In either case, the role of nucleo-olivary input is to weaken olivary coupling by promoting shunting via gap junctions. However, no experimental study has managed to selectively disrupt the nucleo-olivary pathway in vivo.

Identifying the molecular identity of the long-range nucleoolivary neurons is an important goal in understanding cerebellar function. Development offers a window into unique identifiers of neuronal populations. In the cerebellum, neuronal diversity is the product of exquisite temporal patterning within a GABAergic, ventricular progenitor pool (Kim et al., 2008) and the glutamatergic rhombic lip pool, which borders the roof plate of the fourth ventricle (Gilthorpe et al., 2002; Machold and Fishell, 2005). GABAergic and glutamatergic populations express distinct bHLH transcription factors, Ptfla and Atoh1, respectively (Hoshino et al., 2005; Machold and Fishell, 2005; Wang et al., 2005) and give rise to the full complement of cerebellar neurons.

Glutamatergic projection neurons of each cerebellar nucleus are generated in discrete temporal cohorts at the rhombic lip (Green and Wingate, 2014), characterized by distinct markers (Wang et al., 2005; Fink et al., 2006). Neurons migrate tangentially to an intermediate assembly point known as the nuclear transitory zone (NTZ; Altman and Bayer, 1985) and from there to the white matter. By contrast, little is known of the specification, migration, or ultimate molecular identity of the Ptfla-derived inhibitory projection neurons relative to other Ptfla-derived cerebellar cell types (Hoshino et al., 2005; Kim et al., 2008; Zordan et al., 2008) or how integration of inhibitory and excitatory neurons within the nuclei is achieved. Molecular characterization of inhibitory projection neurons thus offers the promise of insights into circuit assembly in addition to a precise functional analysis of how the inferior olive is regulated by the cerebellum.

We chose to address these questions surrounding neuron identity by investigating Sox14, an sex-determining region Y (SRY)-related gene expressed in a range of inhibitory neurons in the CNS (Hargrave et al., 2000; McClellan et al., 2006; Delogu et al., 2012). Recent studies have shown that Sox14 is required for tangential migration of GABAergic precursors in the thalamus and midbrain (Delogu et al., 2012; Jager et al., 2016). We found Sox 14 reporter expression in the lateral and interposed, but not the medial, cerebellar nuclei from E12.5 to P21. Axonal tracing techniques reveal that cerebellar Sox14-expressing cells comprise exclusively nucleo-olivary neurons, generated within the same temporal window as their glutamatergic long-range projecting counterparts. Unilateral ablation of Sox 14 neurons results in motor deficits and impaired motor learning but not in impairment to associative learning.

\section{Materials and Methods}

Animals husbandry and birth-dating experiments. The Sox $14^{G f p /+}$ (Delogu et al., 2012) and Sox $14^{\mathrm{Cre} /+}$ (Jager et al., 2016) mouse lines were maintained in the C57BL/6 background in the animal facilities of King's College London. All mice were housed in Techniplast cages $(32 \times 16 \times$ $14 \mathrm{~cm}$ ) with sawdust (Litaspen premium, Datesand) and basic cage enrichment, consisting of sizzlenest (Datesand) and a cardboard shelter
(LBS Biotech). All mice had ad libitum access to water and food (Rat and Mouse No. 3 Diet for breeders and No. 1 for test mice; Special Diet Services). The housing room was maintained at a constant room temperature $\left(\sim 21^{\circ} \mathrm{C}\right)$ and humidity $(\sim 45 \%)$ and kept under a regular light/ dark schedule with lights on from 8:00 A.M. to 8:00 P.M. (light, 270 lux). All experimental procedures described received internal approval from the King's College London Ethical Committee and were covered by UK Home Office License 70/9042. For birth-dating cells, BrdU (B5002, Sigma) was administered intraperitoneally (in saline, $0.2 \mathrm{mg} \mathrm{g}^{-1}$ ) into a subset of pregnant mice at 9:00 A.M. between E10.5 and E18.5, estimated from the occurrence of a vaginal plug (the morning of the day the plug was detected was designated E0.5). Embryos from uninjected dams were harvested for morphological analysis at E11.5 and E12.5. A proportion of neonatal animals were killed at P0 (decapitation). Some brains were set aside from primary cell culture, whereas the others were immersion fixed in $4 \%$ paraformaldehyde in saline. Pups from BrdU-injected dams were killed at P7. The remaining litters were selected for steroataxic injection at P14 for tract tracing and behavioral experiments or killed at P21 for morphological analysis. At these later stages, mice were killed with 0.6 $\mathrm{ml} / \mathrm{kg}$ pentobarbital sodium $(20 \% \mathrm{w} / \mathrm{v}$; Pentoject) administered intraperitoneally and perfused with $4 \%$ paraformaldehyde in saline. Only adult ( $>8$ weeks) male mice were used for behavioral tests.

Primary cell culture. The entire cerebellum at $\mathrm{P} 0$, comprising cortex and nuclei, was dissected out immediately in ice-cold sterile PBS, transferred into ice-cold HEPES buffer, and dissociated both mechanically and enzymatically (papain, EDTA, DNase, Neurobasal, L-cysteine). A final dissociation step by trituration with a polished glass pipette in Neurobasal medium (Neurobasal, B27, Glutamax, antibiotic-mycotic solution; Invitrogen) resulted in a cell suspension that was plated overnight onto poly-D-lysine-coated (Myat et al., 1996) coverslips at a density of $2 \times 10^{5}$ cells per well and incubated overnight at $37^{\circ} \mathrm{C}$.

Stereotaxic brain injections. P14 animals of both sexes were used for tract-tracing experiments. Only males were used for targeted ablation experiments and behavioral tests. Animals were anesthetized using isoflurane, and injections were made stereotaxically into the cerebellar nuclei, inferior olive, or oculomotor nucleus or combinations of these sites. For anterograde tracing of Sox 14-expressing cells, $0.2-0.8 \mu \mathrm{l}$ of Credependent adeno-associated virus [pAAV-EF1a-DIO-mGFP (serotype 2/1, $5.9 \times 10^{13} \mathrm{vg} / \mathrm{ml}$ ) or pAAV-EF1a-DIO-tdTom (serotype $2 / 1,1.6 \times$ $10^{9} \mathrm{vg} / \mathrm{ml}$ ); a gift from Dr. Botond Roska, Friedrich Miescher Institue for Biomedical Research, Basel, Switzerland] was injected in the brains of Sox $14^{\mathrm{Cre} / \mathrm{+}}$ mice at coordinates relative to lambda $(x, y, z: \pm 2.00,-1.60$, $-3.85 \mathrm{~mm}$ to target the cerebellar nuclei; $\pm 0.10,+0.10,-2.50 \mathrm{~mm}$ to target the oculomotor nucleus; $\pm 0.10,-1.90,-5.00 \mathrm{~mm}$ to target the inferior olive). For retrograde tracing, target nuclei in the brains of Sox $14^{G f p /+}$ mice were injected with $100 \mathrm{nl}$ of fluorescent latex "RetroBead" microsphere solution (Lumafluor). Targeted ablation of Sox $14^{+}$ cells in Sox $14^{\mathrm{Cre} /+}$ mice was achieved by targeted injections of AAVmCherry-flex-dtA (Addgene plasmid number 58536; serotype 2/1, $6.0 \times$ $10^{12} \mathrm{vg} / \mathrm{ml}$ ) for the experimental animals, whereas sham injections were performed using AAV-EF1a-DIO-tdTom in Sox $14^{\text {Cre /+ }}$ mice or AAVmCherry-flex-dtA in Sox $14^{+/+}$mice. AAV-mCherry-flex-dtA encodes a subunit of the diphtheria toxin in the Cre-expressing cells while also promoting the non-Cre-dependent production of a mCherry red fluorescent protein in all cells infected by the virus, thus allowing postmortem analysis of the site of injection.

Behavioral tests. Motor learning and coordination were assessed using a Rota-Rod 47600 testing device (Ugo Basile). Mice were tested over $3 \mathrm{~d}$, with $24 \mathrm{~h}$ between the sessions. On each day, mice underwent three trials at1 $\mathrm{h}$ intervals. On each trial, the rod was set to accelerate from 2 to 40 rpm over $300 \mathrm{~s}$. Latency to fall was measured as the time from the start of the acceleration of the rod to the point the mouse fell onto the sensor below the rod. If the mouse clung to the rod to rotate around with it more than three consecutive rotations instead of falling, this was also deemed the end of the trial, since this implies an inability to maintain locomotion at that speed.

Locomotive performance and associative motor learning were assessed on an Erasmus ladder (version 1.1, Noldus; Vinueza Veloz et al., 2015). This consists of a horizontal ladder of $2 \times 37$ touch-sensitive rungs 
(4 $\mathrm{g}$ threshold) for the left and right sides, with alternate rungs in a descended position to create an alternating stepping pattern with $30 \mathrm{~mm}$ gaps. Motor performance is assessed by the number of missteps (lowered rungs that are stepped on). Each mouse was tested over $10 \mathrm{~d}$, with $4 \mathrm{~d}$ of training to cross the ladder without obstacles, followed by $2 \mathrm{~d}$ of rest and another $4 \mathrm{~d}$ of an associative motor learning test. Each day, 42 trials were performed consecutively for each mouse.

For the associative motor learning paradigm, a third set of rungs whose default position is lowered, were used as obstacles. Based on the prediction of the position of the mouse and the speed of walking, an obstacle rung can be raised by a high-speed pneumatic slide. This perturbation acts as an unconditioned stimulus. A $90 \mathrm{~dB}, 2 \mathrm{kHz}$ tone lasting by default $250 \mathrm{~ms}$ was used as a conditioned stimulus at a fixed interval before the unconditional stimulus. The ladder records the change in step time for each mouse before and after perturbation. The difference between preperturbation and postperturbation step time ( $\Delta$ step time) before and after conditioning are a readout of motor learning (Van Der Giessen et al., 2008).

In situ hybridization and immunolabeling. Primary cell cultures and floating cryosections at $60 \mu \mathrm{m}$ were prepared for immunostaining, whereas $20 \mu \mathrm{m}$ cryosections on slides were prepared for in situ hybridization. In situ hybridization was performed using standard protocols (Myat et al., 1996) with the following riboprobes: Gad1 (IMAGE: 5358787), Gad2 (IMAGE: 4482097), PValb (IMAGE: 4925213), and Calb2 (IMAGE: 4527074). Immunostaining was performed using standard protocols with antibodies against the following: GFP (chicken, 1:10,000; Abcam), dsRed (rabbit, 1:200; Clontech), GABA (rabbit, 1:2000; Sigma-Aldrich), PValb (rabbit, 1:400; Abcam), Calb1 (mouse, 1:400; Abcam), Calb2 (rabbit, 1:200; Abcam), MAP2 (mouse, 1:1000; Sigma-Aldrich), Lhx1/5 (mouse, 1:20; DHB), Pax6 (mouse, 1:100; DHB), BrdU (rat, 1:200; Bio-Rad), vesciular GABA transporter (vGAT) (rabbit, 1:600; Synaptic Systems), and appropriate fluorescent goat Alexa Fluor 568 anti-rat and Alexa Fluor 488 anti-chicken secondary antibodies (Invitrogen). For animals from BrdU-injected dams, cryosections were preincubated in $1 \mathrm{M} \mathrm{HCl}$ in $\mathrm{H}_{2} \mathrm{O}$ at $45^{\circ} \mathrm{C}$ for $30 \mathrm{~min}$.

Imaging and analysis. Labeled brains were imaged on a compound epifluorescence microscope (Zeiss Axio Imager 2712) equipped with a Zeiss ApoTome, a spinning-disk confocal microscope (Nikon Eclipse Ti Inverted), or a laser-scanning confocal microscope (Olympus Fluoview AX70, Nikon Eclipse Ni-E Upright).

Experimental design and statistical analysis. To control for the behavioral results, only male mice were used for the ablation experiment. Twenty Sox $14^{\mathrm{Cre} /+}$ mice and 20 Sox $14^{+/+}$mice were used. Either Credependent AAV-mCherry-flex-dtA or AAV-DIO-tdTom (control) was injected bilaterally into the cerebellar nuclei of both genotypes, thus creating one experimental group and three control groups. To ensure statistical power is maximized, while minimizing the number of animals used, more mice were given injections of AAV-mCherry-flex-dtA (Sox $14^{\mathrm{Cre} /+}, n=16$; Sox $14^{+/+}, n=12$ ) than AAV-DIO-tdTom (Sox $14^{\mathrm{Cre} /+}, n=4$; Sox $14^{+/+}, n=8$ ).

To gauge the size of the Sox $14^{+}$cells relative to the cell types described in other literature (Chan-Palay, 1977; Legendre and Courville, 1987; Aizenman et al., 2003; Uusisaari et al., 2007; Bagnall et al., 2009; Uusisaari and Knöpfel, 2012; Najac and Raman, 2015), a sample of cells (210 cells across $n=5$ brains) was measured for soma size as defined by the crosssectional area of the cell body on the image plane and the mean diameter. To measure the approximate size of cell soma, the selection tools were used to draw around the cell soma. The "Measure" tool in ImageJ was set to measure the area of the selection (taken as the soma cross-sectional area) as well as the "Fit ellipse" measurement, which reports the major and minor axes of the best-fitting ellipse as the minimum and maximum diameters of the selected area. The soma diameter was calculated by taking the average of the maximum and minimum diameter of each soma. For counting the proportion of coexpression of immunoreactivity, the "cell counter" plugin was used to manually label each cell in an image.

Statistics and charts were created using Prism 7 software (GraphPad). To analyze the behavioral data, all the control animals were pooled into one group (“Sham”). For normally distributed results, Student's $t$ test and two-way ANOVAs were conducted with Bonferroni's multiple comparisons test or the corrected method of Benjamini and Yekutieli to control the false discovery rate. Figures present the mean \pm SEM. For nonparametric data, the Mann-Whitney $U$ test was used to test whether the independent sham and experimental groups have the same distribution, and the figures present the median with a 95\% confidence limit.

Automated counts of Gad1-positive cells were used in cell ablation experiments using defined regions of interest (ROIs) and the "Find Maxima ..." function in ImageJ, using a macro to automate the count. This produced a tabulation of the number of cells detected in each ROI, while a flattened image with each detected cell was saved to check for errors in the counting. If a particular image had a severe miscount (over or under the estimate of the number of cells) because of inconsistency in staining, the detection threshold was adjusted accordingly.

\section{Results}

\section{Sox14 identifies a cerebellar nucleus cell type exclusive to the} lateral and interpositus nuclei

We found expression of Sox 14 in the cerebellum of Sox $14^{G \mathrm{fp} /+}$ mice from E12.5 to P28 (data not shown). A series of coronal sections at P14 from rostral to caudal shows that Sox $14^{+}$cells are distributed irregularly in the lateral nucleus, but with a higher density ventromedially (Fig. $1 A$ ). Midway through the cerebellum (Fig. $1 B, C$ ), distribution can be directly compared in the lateral, interposed, and medial cerebellar nuclei, with the superior vestibular nucleus and vestibulocerebellar nucleus that lie directly below the posterior interposed nucleus. Sox $14^{+}$cells are sparsest in the dorsal regions of the nuclei, particularly in the dorsolateral and anterior interposed nuclei. In contrast, Sox $14^{+}$ cells are present at a high density in the parvicellular domain on the ventral border of the lateral nucleus. Sox14-positive cells are also found in superior vestibular and vestibulocerebellar nuclei. The medial nucleus does not contain Sox $14^{+}$cells, with the exception of a scattering of cells in the rostroventral medial nucleus (Fig. 1C, boxed region and inset). In more caudal sections, the medial nucleus is devoid of Sox $14^{+}$cells (Fig. 1D).

\section{Sox14-positive cells comprise at least two molecularly distinct populations of small GABAergic neurons}

We used immunohistochemistry and in situ hybridization to examine the molecular phenotype of Sox $14^{+}$cells in the Sox $14^{\mathrm{Gfp} /+}$ cerebellum at P0 and P21. At P21, GFP and GABA colocalize in the cytoplasm of Sox $14^{+}$neurons (Fig. $2 A$, white arrowheads). Because the of density of GABA-positive axon terminals within the nucleus neuropil, colocalization of GABA with GFP was confirmed by immunocytochemistry on primary cultures of dissociated P0 Sox $14^{G f p /+}$ cerebellar tissue (Fig. $2 B$ ). In all instances, GFP colocalized with GABA and the pan-neuronal marker MAP2 $(n=21)$. Detection of Gad1 (Fig. 2C) and Gad2 (Fig. 2D) mRNAs by in situ hybridization and GFP immunohistochemistry on Sox $14^{G \mathrm{fp} /+}$ at $\mathrm{P} 21$ revealed that Sox $14^{+}$neurons are a subset of the entire GABAergic population within the cerebellar nuclei. In the medial nucleus, all Gad1-positive cells are GFP negative (data not shown), consistent with the observation that Sox $14^{+}$neurons are absent from this nucleus. The Sox $14^{-}$fraction within the other cerebellar nuclei accounts for 27\% of Gad1-positive cells and $20 \%$ of Gad2-positive cells ( $n=5$ brains).

Sox $14^{+}$neurons are negative for PValb (Fig. 2E), Calb1 (Fig. $2 F$ ), while some express Calb2 (Fig. 2G). In situ hybridization revealed that $\mathrm{PValb}^{+}$neurons are larger in size (Fig. $2 \mathrm{H}$ ) and contrast the regional distribution of Sox $14^{+}$neurons: $\mathrm{GFP}^{-} /$ $\mathrm{PValb}^{+}$mostly lie in the dorsolateral, posterior interposed, and medial nuclei (Fig. $2 F$ ), whereas the smaller $\mathrm{GFP}^{+} / \mathrm{PValb}^{-}$cells are most populous in the ventromedial region of the lateral nu- 

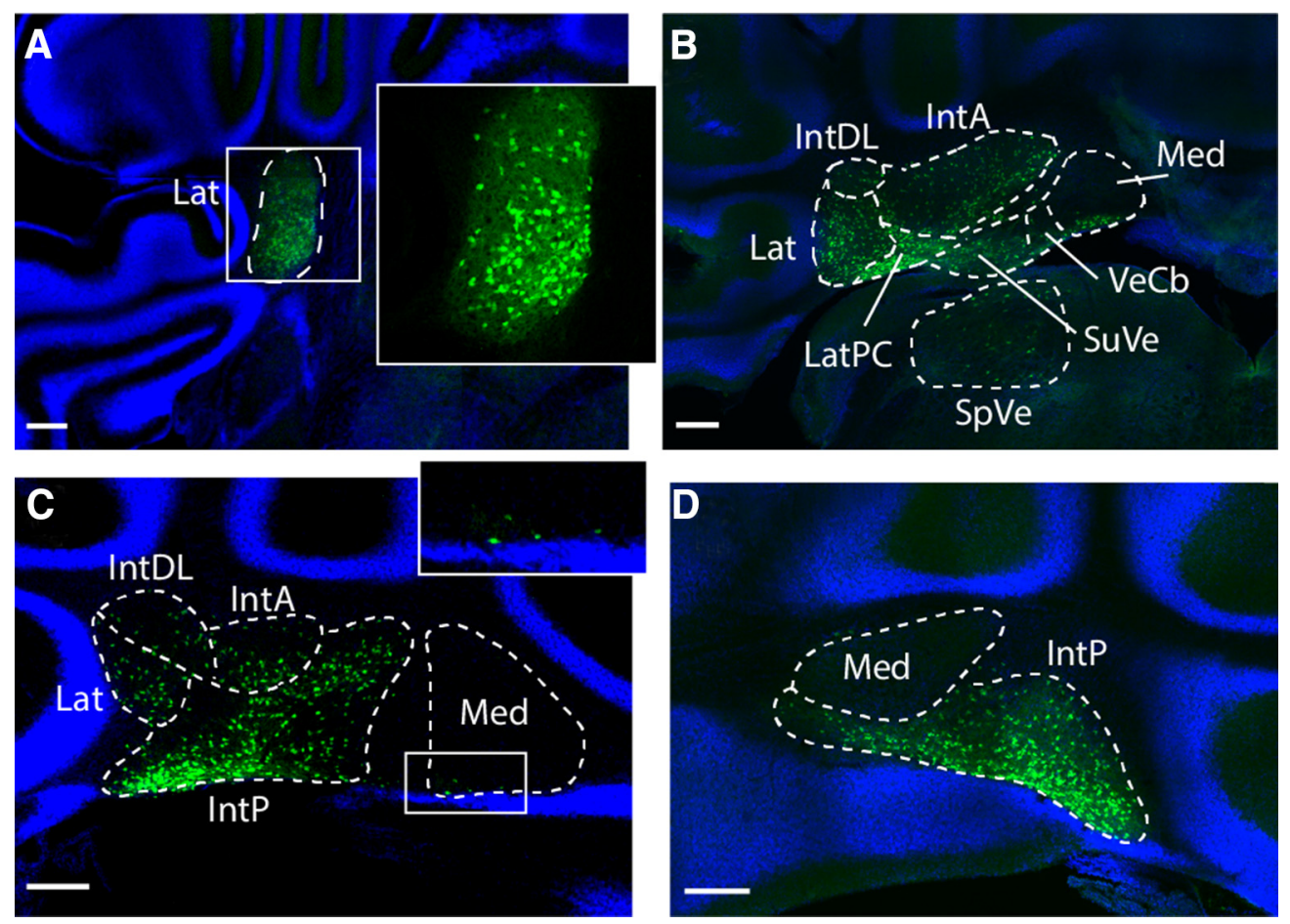

Figure 1. Sox14 marks a subset cells in cerebellar nuclei. P21 Sox $14^{G \text { frp } /+}$ coronal sections show the cerebellum from rostral to caudal. $\boldsymbol{A}$, Only the lateral cerebellar nucleus is seen in rostral sections. Sox $14^{+}$cells are found in the cerebellar nucleus, and these cells are distributed unevenly, seen clearly in the magnified image (inset). $\boldsymbol{B}$, The lateral nucleus merges with the interposed nuclei and the vestibular nuclei: SuVe, superior vestibular nuclei; VeCb, vestibulocerebellar nuclei. There are Sox $14^{+}$cells throughout, except in the dorsal parts of the medial nucleus. $C$, More caudally, the lateral and anterior interposed nuclei recede so to only occupy a small dorsolateral domain, whereas the posterior interposed nucleus takes over. Small numbers of Sox $14^{+}$cells are seen in the ventral edge of the medial nucleus (inset). $\boldsymbol{D}$, Most caudally, the medial nucleus is seen clearly as an almond shape above the posterior interposed nucleus. Though the shape of the nucleus is well defined by the background staining, again no Sox $14^{+}$cells are seen in this region. Lat, Lateral nucleus; LatPC, parvicellular lateral nucleus; IntDL, dorsolateral interposed nucleus; IntA, anterior interposed nucleus; IntP, posterior interposed nucleus; Med, medial nucleus; VN, vestibular nucleus; RN, reticular nucleus. Scale bar, $200 \mu \mathrm{m}$.

cleus. In situ hybridization for Calb2 reveals two populations of Sox $14^{+}$neurons within the lateral cerebellar nucleus; the $\mathrm{Calb2}^{+} / \mathrm{GFP}^{+}$neurons reside in the ventromedial regions whereas the rest of the Sox $14^{+}$neurons throughout the nuclei are $\mathrm{Calb2}^{-}$(Fig. 2I). Other Calb2 ${ }^{+}$cells are seen in the superior vestibular nuclei and vestibulocerebellar nuclei, as well as the cochlear nuclei more ventrally.

We used in situ hybridization data on brain slices ( $n=5$ brains per probe) to map the average relative soma sizes of $\mathrm{GFP}^{+}$/ $\mathrm{Gad1}^{+}, \mathrm{GFP}^{-} / \mathrm{Gad1}^{+}$, and $\mathrm{GFP}^{-} / \mathrm{PValb}^{+}$cells in terms of mean cross-sectional area and diameter. The mean soma crosssectional areas are as follows: $\mathrm{GFP}^{+} / \mathrm{Gadl}^{+}, 153.4 \pm 5.8 \mu \mathrm{m}^{2}$;

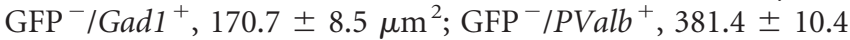
$\mu \mathrm{m}^{2}$ (mean $\pm \mathrm{SEM}$ ). The mean soma diameters are as follows: $\mathrm{GFP}^{+} / \mathrm{Gad}^{+}, 14.1 \pm 0.3 \mu \mathrm{m} ; \mathrm{GFP}^{-} / \mathrm{Gad}^{+}, 15.1 \pm 0.4 \mu \mathrm{m}$; $\mathrm{GFP}^{-} / \mathrm{PValb}^{+}, 22.3 \pm 0.3 \mu \mathrm{m}$ (mean $\pm \mathrm{SEM}$ ). Figure $2 J$ shows that although the mean soma diameters are larger for $\mathrm{GFP}^{-}$/ $\mathrm{Gad}^{+}{ }^{+}$cells compared with $\mathrm{GFP}^{+} / \mathrm{Gad}^{+}$cells, the two populations have overlapping diameter distributions that are not significantly different. This is more clearly seen in a scatterplot of diameters (Fig. $2 \mathrm{~K}$ ) where the whole range of $\mathrm{GFP}^{-} / \mathrm{Gad}^{+}$ cells measured falls within the large range of $\mathrm{GFP}^{+} / \mathrm{Gad}^{+}$cell diameters.

\section{Sox14-positive neurons appear to be exclusively projection neurons}

To investigate the trajectory of Sox $14^{+}$GABAergic nuclear axons, the lateral cerebellar nuclei of Sox $14^{\mathrm{Cre} /+}$ heterozygous mice were unilaterally and stereotaxically targeted for injection with AAV-EF1a-DIO-mGFP tracer at P14 and collected for analysis at
P28 ( $n=14$; Fig. $3 A$ ). The majority of labeled axons of these cells project decussate at the superior cerebellar peduncle (Fig. 3B, xscp), as the "horseshoe-shaped commissure of Wernekinck," and descend to terminate in the contralateral inferior olive (Fig. $3 C$ ). Ipsilaterally, ascending axons also extend into the midbrain, terminating in the oculomotor nucleus (Fig. 3D), whereas a small population of descending axons target the inferior olive.

To assess the respective contributions of contralateral and ipsilateral projections to inferior olive subnuclei, Sox $14^{\mathrm{Cre} /+}$ brains were injected with AAV-EF1a-DIO-mGFP in the cerebellar nuclei of one hemisphere and with AAV-EF1a-DIO-tdTom at symmetrical coordinates on the other side of the brain. Fluorescently labeled axon terminals reveal a contralateral and a relatively sparse ipsilateral projection pattern (Fig. 3E). The principal olive, the ventrolateral protrusion, and the cap of Kooy of the medial nucleus receive a bilateral, predominantly contralateral input. Nucleo-olivary axons leave gaps where olivary cells reside, as confirmed by nuclear DAPI staining (Fig. $3 F$ ). Axonal boutons cluster in acellular spaces suggesting that synapses are concentrated distant to the cell body.

To examine whether the projections to the oculomotor nucleus are also derived from cerebellar Sox $14^{+}$neurons, green fluorescent latex microspheres (RetroBeads) were injected into the ipsilateral oculomotor nuclei (Fig. 4A) and red RetroBeads were injected into the contralateral inferior olive (Fig. 4B) of Sox $14^{G f p /+}$ mice $(n=10)$. Retrogradely transported green RetroBeads from the oculomotor nucleus were not transported to the cerebellar nuclei, but rather were found just lateral to the superior vestibular nucleus, directly ventral to the parvicellular lateral cerebellar nucleus. This region corresponds to nucleus $\mathrm{Y}$ 

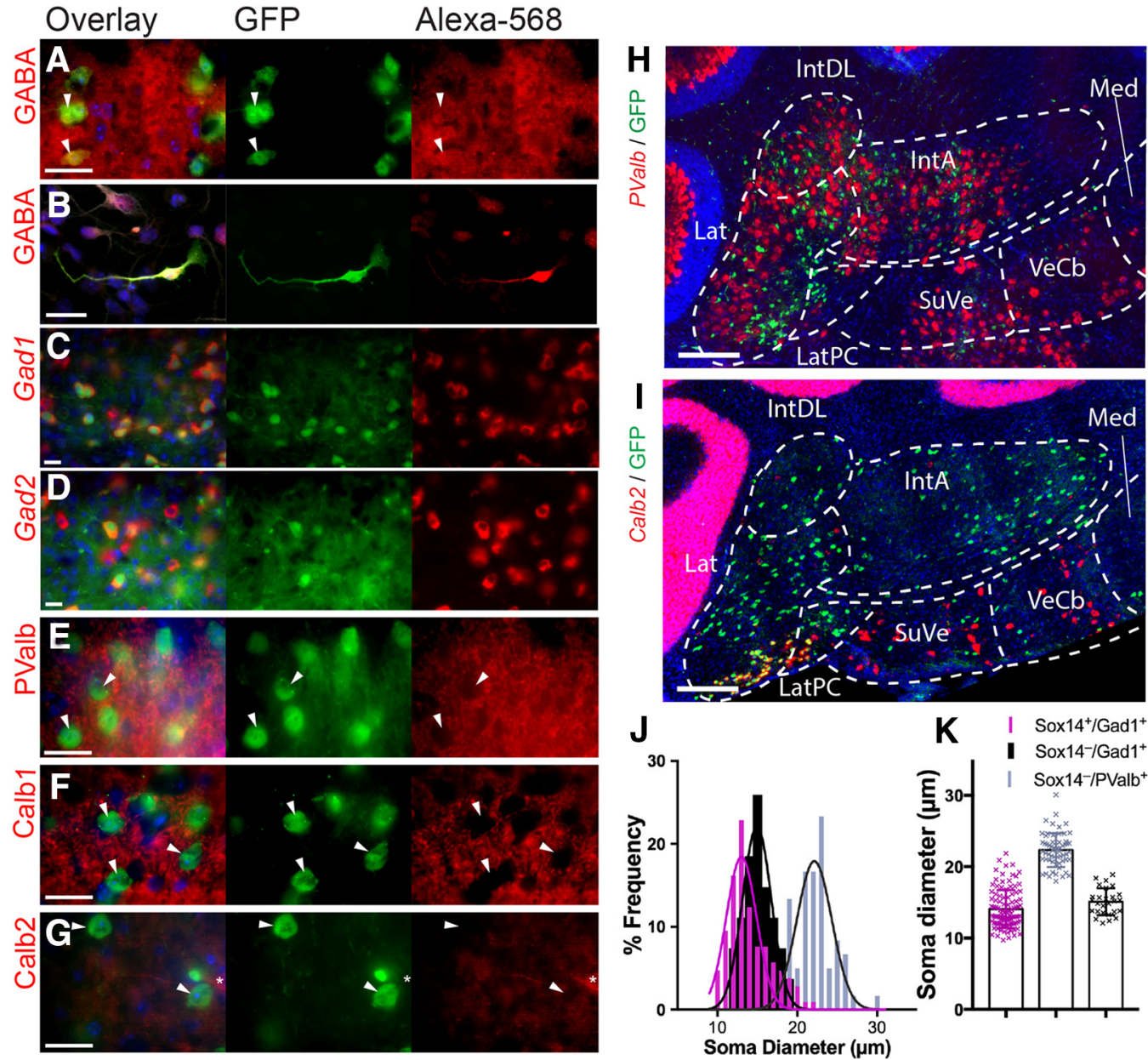

Figure 2. In the cerebellar nuclei, Sox14 are small, exclusively GABAergic, PV-ve neurons GFP versus PValb, GANA CALB1,2, GABA, GAD1, and GAD2. A-I, Comparison of Sox14:GFP with other known cell markers by immunohistochemistry or in situ hybridization in Sox $14{ }^{\mathrm{Gfp} /+} \mathrm{P} 21$ sections $(\boldsymbol{A}, \boldsymbol{C}-\boldsymbol{I})$ and primary cell culture of brain tissue from Sox $14{ }^{\mathrm{Gfp} /+} \mathrm{P} 0$ neonates $(\boldsymbol{B})$. Immunostaining for GABA $(\boldsymbol{A}, \boldsymbol{B})$, MAP2 blue label in $(\boldsymbol{B}), \operatorname{Gad} 1(\boldsymbol{C})$, Gad2 (D), PValb (E), Calb1 $(\boldsymbol{F})$, and Calb2 (G), imaged at 100 $\times(40 \times$ for in situ hybridization) magnification of the lateral nucleus. The columns show the overlay, then GFP only and Alexa Fluor 568 only. The white arrowheads show examples of GFP ${ }^{+}$cells that colocalize with GABA, Gad1, and Gad2 but not PValb, Calb1, or Calb2. There is little immunoreactivity for Calb2 within the cerebellar nuclei $(\boldsymbol{G})$, but a single $\mathrm{GFP}^{-} / \mathrm{Calb2}^{+}$cell is seen, denoted with an asterisk. $\boldsymbol{H}, \boldsymbol{I}, \mathbf{I}$ situ hybridization against $P V a l b(\boldsymbol{H})$ and $\mathrm{Calb2}(\boldsymbol{I})$ demonstrates the distribution of the different cell types. Lat, Lateral nucleus; LatPC, parvicellular lateral nucleus; IntDL, dorsolateral interposed nucleus; IntA, anterior interposed nucleus; Med, medial nucleus; SuVe, superior vestibular nuclei; VeCb, vestibulocerebellar nuclei. $\boldsymbol{H}$, PValb expression is observed in complementary large nuclear cells to GFP + cells. I, Calb2 expression is mostly observed in two distinct populations within the Sox $14^{+}$cells of the cerebellar nuclei. Sox $14^{-} / \mathrm{Calb2} 2^{+}$are seen in the central parts of the lateral nucleus, whereas Sox $14^{+} / \mathrm{Calb2} 2^{+}$exist in a dense cluster in the

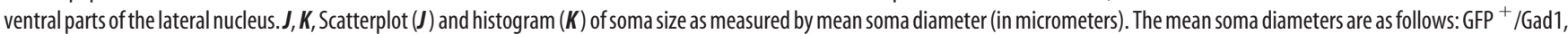
$14.1 \pm 0.3 \mu \mathrm{m} ; \mathrm{GFP}^{-} / \mathrm{Gad1}^{+}, 15.1 \pm 0.4 \mu \mathrm{m}$; and GFP ${ }^{-} / \mathrm{PValb}^{+}, 22.3 \pm 0.3 \mu \mathrm{m}$ (mean \pm SEM). The peak frequency for cell diameter of both GFP ${ }^{+}$and GFP ${ }^{-}$Gad 1 populations is very similar. In addition, the larger GFP ${ }^{+}$cells overlap with the $\mathrm{PValb}^{+}$population, demonstrating that size is not a sufficient determinant of cell type.

(or Group Y) and contains both Sox14-positive and -negative cells that project to the oculomotor nucleus (Fig. 4C). Both red and green RetroBeads label Sox $14^{+}$neurons, but no neurons are colabeled with both retrograde tracers (Fig. $4 C^{\prime}$ ).

To determine whether Sox $14^{+}$neurons make up the entire GABAergic efferent projection to the inferior olive, green RetroBeads were injected unilaterally into the inferior olive of Sox $14^{\mathrm{Gfp} /+}$ mice at P19 (Fig. 4D), and their retrograde transport was examined after $2 \mathrm{~d}$ at P21. Within the lateral and interposed nuclei, RetroBeads were detected exclusively in Sox $14^{+}$neurons (Fig. 4E). We conclude that Sox14-expressing cells are the only cell type in the lateral and interposed cerebellar nuclei that project to the inferior olive. However, we cannot formally exclude the possibility that some Sox $14^{+}$cells may be interneurons. The ipsilateral and contralateral cell bodies labeled by the same injection site have a similar distribution across the cerebellar nuclei, whereas the number of cells in which beads are detected are noticeably fewer in the ipsilateral nucleus (Fig. $4 F$ ).
Figure $4 G$ schematically summarizes the projection patterns of Sox $14^{+}$neurons in the cerebellar and vestibular nuclei (Fig. $4 G$, left) and their targeting of different subnuclei within the inferior olive (Fig. $4 G$, right), revealed by anterograde and retrograde tracing. Projections from Sox $14^{+}$neurons in the lateral cerebellar nucleus mainly target the principle olive and the dorsomedial cell group, the interposed nuclei project to the medial olivary nucleus and the dorsal olivary nucleus, and the vestibular nuclei target the cap of Kooy of the medial nucleus and the ventrolateral protrusion.

\section{Cerebellar Sox14-positive neurons are generated between} E10.5 and E11.5 and accumulate at the NTZ

In the developing rhombencepahlon, GFP in the cerebellum of Sox $14^{G / f p /+}$ is first seen at E10.5 and limited, until E11.5, to a ventral column of cells spanning the length of the hindbrain (Fig. $5 A, B)$. GFP expression is first seen in the cerebellar anlage at E12.5 in a band of cells in dorsal rhombomere 1, distal to the 

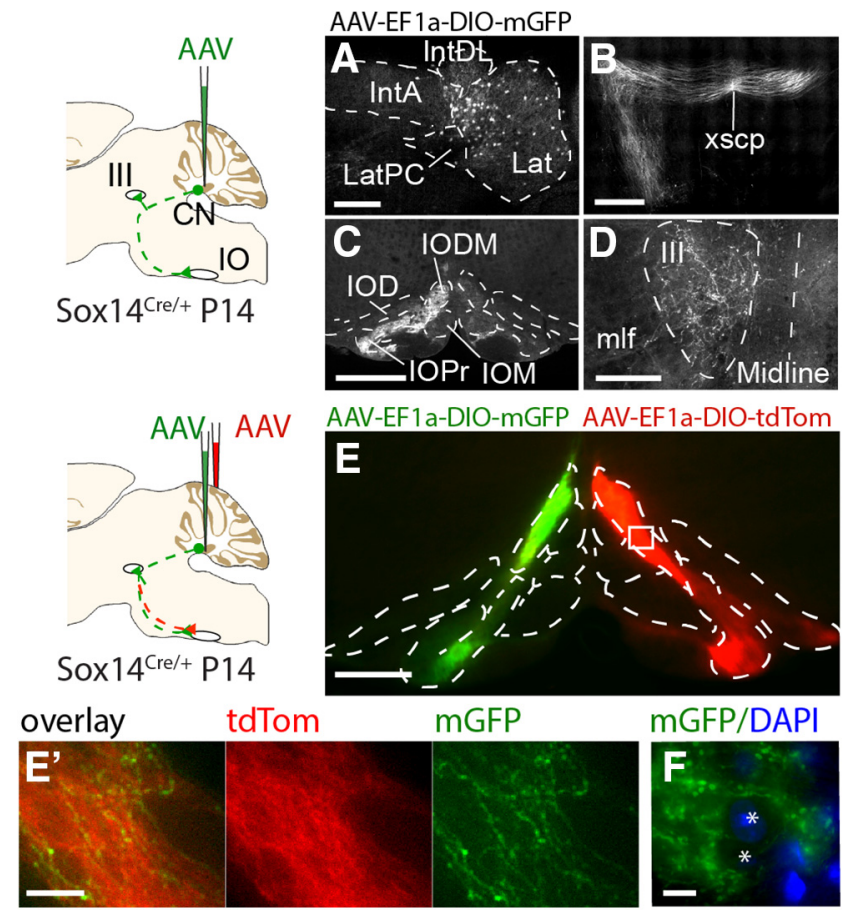

Figure 3. Anterograde labeling of Sox 14 projections identifies targets in the midbrain and inferior olive. $\boldsymbol{A}-\boldsymbol{D}$, Unilateral injections of AAV-EF1a-DI0-mGFP targeted the lateral cerebellar nucleus $(\boldsymbol{A})$, and projections were observed crossing the midline at the decussation of the superior cerebellar peduncle (xscp, $\boldsymbol{B})$ and terminating in the contralateral inferior olive $(\boldsymbol{C})$ and the ipsilateral oculomotor nucleus (III, D). E, F, Bilateral injections of AAV-EF1a-DI0-mGFP and AAV-EF1a-DI0-TdTomato into the lateral cerebellar nucleus on either hemisphere show that axonal projections from each cerebellar hemisphere are bilateral, targeting both the ipsilateral and contralateral inferior olive though denser fluorescence on the contralateral side (E). Although the projections clearly terminate in the contralateral olive, axons with synaptic boutons can be seen in the ipsilateral side contacting the same range of cells. A higher-magnification view is shown in $\boldsymbol{E}^{\prime}$. $\boldsymbol{F}$, High magnification image shows mGFP-expressing axons bypassing spaces where olivary cells reside (shown by blue DAPI staining, asterisks). Scale bars: $\boldsymbol{E}^{\prime}, \boldsymbol{F}, 20$ $\mu \mathrm{m} ; \boldsymbol{A}, \boldsymbol{E}, 200 \mu \mathrm{m} ; \boldsymbol{B}-\boldsymbol{D}, 500 \mu \mathrm{m}$. Lat, Lateral nucleus; LatPC, parvicellular lateral nucleus; IntDL, dorsolateral interposed nucleus; IntA, anterior interposed nucleus; 10 , inferior olive; IOD, inferior olive dorsal nucleus; IODM, inferior olive dorsomedial cell group; IOM, inferior olive medial nucleus; IOPr, inferior olive principal nucleus; $\mathrm{CN}$, cerebellar nucleus; mlf, medial longitudinal fascicle.

rhombic lip (Fig. 5C). The precise birth date of Sox $14^{+}$neurons was determined by injecting BrdU into pregnant dams at successive stages from E10.5 to E18.5. The brains of the mice pups were collected and analyzed at P7. GFP-labeled neurons incorporated BrdU for injections administered at E10.5 (Fig. 5D) and E11.5 (data not shown). For injections made at E12.5 or later, no BrdU staining was seen in GFP-labeled cells (Fig. $5 E$ ). Within the cerebellar cortex, BrdU was detected in Purkinje cells for injections made at E11.5, E12.5, and E13.5, showing that nucleo-olivary neurons are born before GABAergic Purkinje cells and interneurons (data not shown). Sox $14^{-} / \mathrm{BrdU}^{+}$cells are seen in the cerebellar nuclei throughout all the injections, showing that the other nuclear cell types are also generated during this time window.

Sox $14^{G f p /+}$ E12.5 sagittal slices were stained using antibodies against Lhx1/5 and Pax6, which are expressed by well characterized neuronal cell types of the developing cerebellum. Lhxl/5 is expressed in Purkinje cells that are derived from the ventricular zone (Morales and Hatten, 2006), whereas Pax6 expression defines the glutamatergic cell populations that migrate from the rhombic lip, including nucleus neurons that accumulate at the
NTZ. At E12.5, GFP-expressing cells also label for Lhx1/5 (Fig. $5 F$ ) and form a distinct pool of neurons superficial to the majority of $L h \times 1 / 5^{+}$cells, which represent Purkinje cells that are radially migrating from the ventricular zone. At high magnification, it is clear that the processes of $\mathrm{GFP}^{+} / \mathrm{Lhx} 1 / 5^{+}$neurons are aligned tangentially rather than radially. Staining for Pax6 (Fig. $5 G$ ) reveals that $\mathrm{GFP}^{+}$cells lie adjacent and inferior to the glutamatergic nuclear neurons of the NTZ, which are known to express Pax6 and tangentially migrate from the rhombic lip. Thus, Sox $14^{+}$cells do not coexpress Pax6 and are distinct from the rhombic lip derivatives. The distribution of Sox 14 cells with respect to the NTZ is shown schematically for an E12.5 brain in Figure $5 \mathrm{H}$.

Although the precise time course of the migration of GABAe$\operatorname{rgic}\left(\right.$ Sox $\left.14^{+}\right)$and glutamatergic $\left(\mathrm{Pax}^{+}\right)$nuclear populations to form the cerebellar nuclei could not be determined, an analysis of the Sox $14^{G f p / G f p}$ (knock-out) mouse at P0 indicates that migration of Sox $14^{+}$neurons stalls before reaching their final location in the absence of a functional Sox 14 allele. At P0, the presumptive boundaries of cerebellar nuclei can already be traced in the cerebellum of a Sox $14^{G f p /+}$ brain (Fig. 5I, $I^{\prime}$ ). Conversely, in P0 Sox $14^{G f p / G f p}$ mice, GFP-expressing cells accumulate at the margins of interposed and lateral nuclei and are excluded from their central regions (Fig. 5J, asterisk). In adult (P42) mice, the normal high density of vGAT labeling in the inferior olive (Fig. $5 K$ ) is decreased in mutant mice (Fig. $5 L, M$ ), consistent with a loss of GABAergic input from Sox14-positive projection neurons.

\section{Targeted ablation of Sox14 cells leads to motor and motor learning deficits}

Sox $14^{+}$neuron-specific cell ablation in the cerebellar nuclei was achieved by conditional expression of diphtheria toxin A. At P14, male mice were given injections of Cre-dependent AAVmCherry-flex-dtA (Sox $14^{\text {Cre/+}}, n=16$; Sox $14^{+/+}, n=12$ ) or control marker virus AAV-DIO-tdTom (Sox $14^{\mathrm{Cre} /+}, n=4$; Sox $14^{+/+}, n=8$ ). Each animal was subjected to a suite of behavioral tests from 8 weeks old ( 6 weeks after injection), and the postmortem brains were analyzed to assess the extent of Sox $14^{+}$ neuron ablation in each animal. Targeting was assessed by mCherry fluorescence and revealed that the anterior interposed nucleus on either side was the most frequently targeted nucleus ( $n=26$ of 32) whereas fewer injections hit the medial ( $n=13$ of 32 ) and posterior ( $n=14$ of 32) interposed nuclei. Off-target injections to the vestibular nuclei ( $n=17$ of 32 ) were a potentially confounding factor in motor testing. A control density map of $\mathrm{Gad} 1^{+}$neurons was constructed from cerebellar nuclei of sham-injected littermates $(n=24)$ and used to estimate the reduction in Sox $14^{+}$neurons after cre-dependent dtA expression (Fig. 6A). As expected from mCherry distribution, when cell survival is assessed in the entire experimental population $(n=16)$, average loss is differentially highest in the anterior interposed nucleus (Fig. 6B). Mice with $>70 \%$ loss in $\mathrm{Gad}^{+}$cells $(n=6)$ were retrospectively identified as a distinct group (Fig. 6C).

Motor learning was measured as latency to fall in an accelerating rotarod task. Fig. $6 D$ shows the assessment of all experimental animals against the sham-injected group, whereas Fig. $6 E$ only shows the motor data for the selected experimental subgroup. Although the experimentally ablated animals display an acquisition curve over time, similar to the sham controls, and start from similar levels of latency on day 1, the latency to fall in the experimental group was significantly shorter at day 2 and at day 3 compared with sham scores on those days $(p=0.0324$ and $p=$ 0.0374 , respectively). Overall, the latency to fall was significantly 


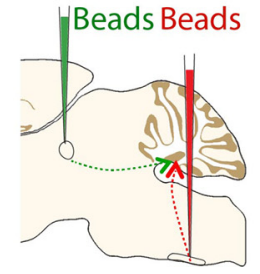

Sox $14^{\mathrm{Gfp} /+} \mathrm{P} 19$
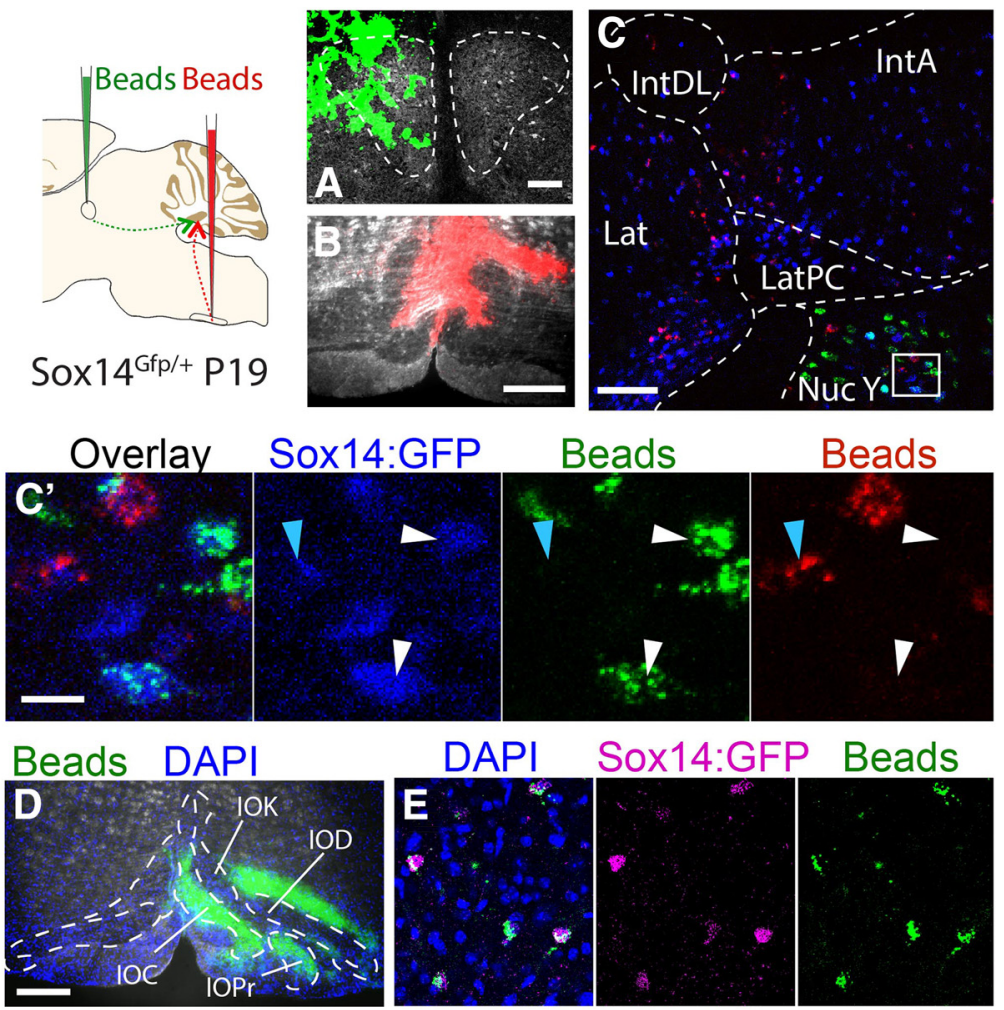

Beads
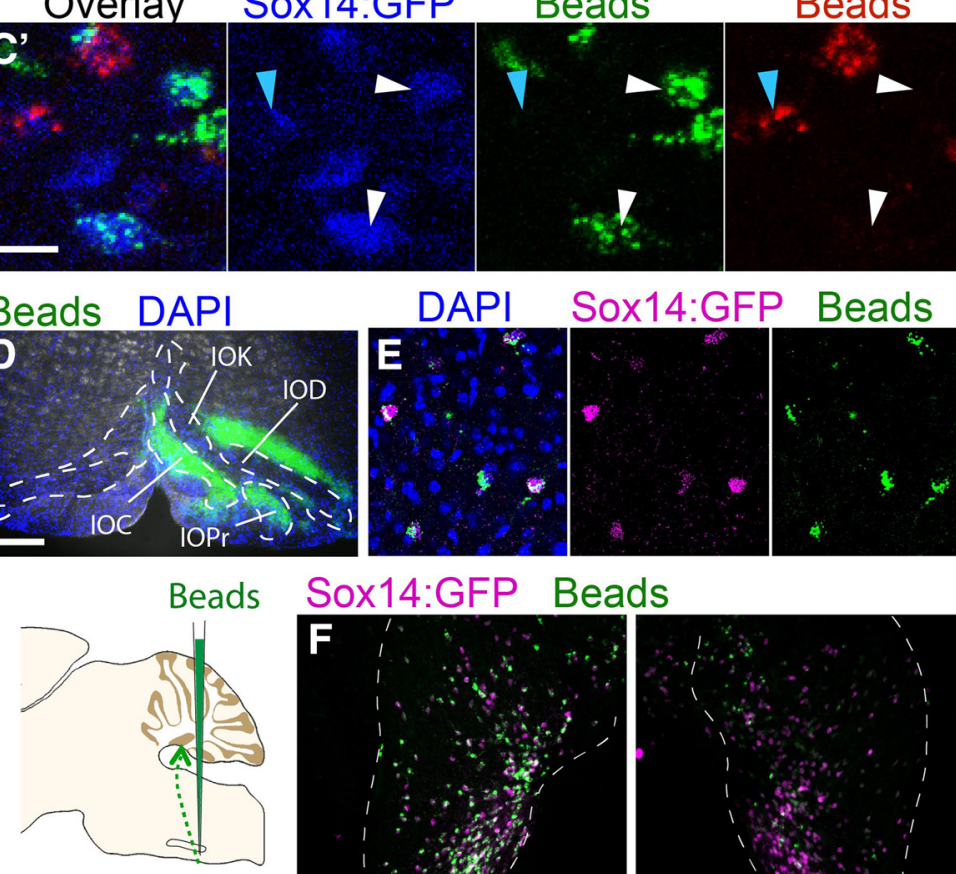

Sox $14^{\mathrm{Gfp} /+} \mathrm{P} 19$
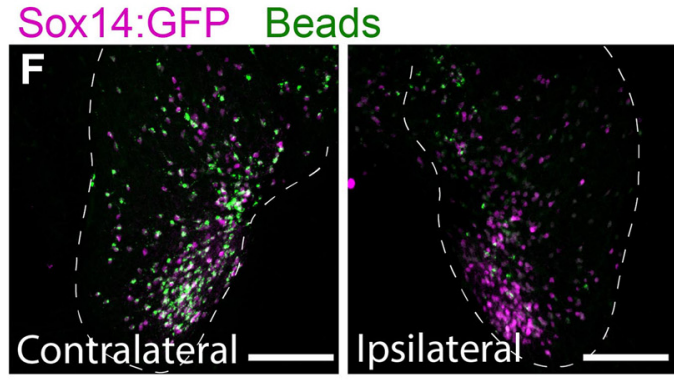

\section{G Cerebellar and}
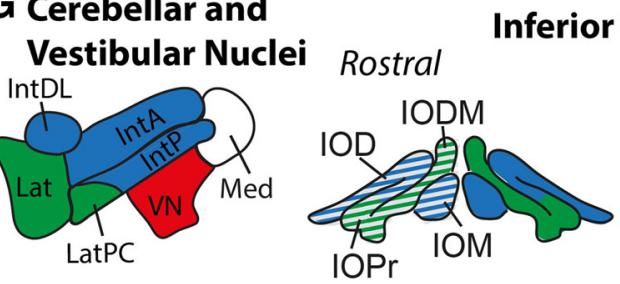

Olive

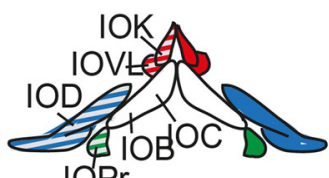

Figure 4. Retrograde labeling identifies distinct Sox14 projection populations. $\boldsymbol{A}, \boldsymbol{B}$, Injections of green RetroBeads into the ipsilateral oculomotor nucleus $(\boldsymbol{A})$ and red RetroBeads into the contralateral inferior olive $(\boldsymbol{B})$ of the Sox $14{ }^{\mathrm{Gfp} /+}$ mouse. $\boldsymbol{C}$, The cerebellar nucleus and surrounding regions. Scale bar, $100 \mu \mathrm{m}$. Endogenous Sox14:GFP was stained with a far-red secondary antibody and is shown in blue. Red RetroBeads were found in Sox14:GFP ${ }^{+}$cells of the cerebellar nucleus, whereas green RetroBeads were only observed in the vestibular nuclei. The nucleus Y region of the vestibularnuclei contains Sox14:GFP ${ }^{+}$cells that colabel with either green RetroBeads or red RetroBeads, but never both colors in one cell $\left(\boldsymbol{C}^{\prime}\right)$. $\boldsymbol{D}$, Unilateral injection of green RetroBeads into the inferior olive of a Sox14 ${ }^{\text {Gfp/+ }}$ mouse at P19. $\boldsymbol{E}, \boldsymbol{F}$, Green RetroBeads were observed in the cerebellar nuclei only in cells that express Sox14:GFP (in magenta). The differential distribution of RetroBeads found in the contralateral and ipsilateral cerebellar nuclei $(\boldsymbol{F})$ shows that projections to the inferior olive come from similar regions of both hemispheres but fewer cells contribute to the ipsilateral olive. G, Summary of Sox $14^{+}$nucleo-olivary topography shown in $A A V$ and RetroBead injections. The nucleo-olivary neurons of the lateral cerebellar nucleus (green) project to the principle olive and the dorsomedial cell group. The nucleo-olivary neurons of the interposed cerebellar nuclei (blue) project to the medial olivary nucleus and the dorsal olivary nucleus. The Sox $14^{+}$neurons of the vestibular nuclei (red) project to the cap of Kooy of the medial nucleus and the ventrolateral protrusion. No Sox $14^{+}$neurons were observed from the medial cerebellar nucleus. All the projections were seen bilaterally in the inferior olive, but the contralateral contribution was consistently more intense (solid color) compared with the ipsilateral contribution (stripe pattern). Scale bars: $\boldsymbol{C}^{\prime}, 20 \mu \mathrm{m} ; \boldsymbol{A}, 50 \mu \mathrm{m} ; \boldsymbol{B}, \boldsymbol{D}, \boldsymbol{F}, 200 \mu \mathrm{m}$. Lat, Lateral nucleus; LatPC, parvicellular lateral nucleus; IntDL, dorsolateral interposed nucleus; IntA, anterior interposed nucleus; NucY, nucleus $Y ; 10 C$, inferior olive subnucleus C of medial nucleus; IOD, inferior olive dorsal nucleus; IOK, inferior olive cap of Kooy of the medial nucleus; IOPr, inferior olive principal nucleus; IODM, inferior olive dorsomedial cell group; IOM, inferior olive medial nucleus; IOB, inferior olive subnucleus B of medial nucleus; IOVL, inferior olive ventrolateral protrusion; Med, medial nucleus; VN, vestibular nucleus. shorter than in animals receiving injections of control virus (two-way ANOVA, main effect of ablation, $F_{(1,120)}=4.479$, $p=0.0064)$. These results show that ablation of Sox14-positive cells reduces the ability to acquire the motor skills needed to stay on the accelerating rod.

To test basic motor coordination, the number of missteps in a smaller group of sham-injected littermates $(n=10)$ and experimentally ablated mice $(n=10)$ was assessed on introduction to the regularly spaced, pressure-sensitive rungs $(30 \mathrm{~mm}$ gaps) on an Erasmus ladder (42 consecutive trials). Experimental animals with ablated nuclei exhibited a significantly higher median percentage of missteps on day 1 (Fig. $6 F, p=0.0433$; Fig. $6 G$ ). This difference is ameliorated over the subsequent days of trials on the ladder, and there is no significant difference median percentage of missteps after training by day 4 (data not shown). Over these training days, experimental animals and shaminjected animals showed a similar overall average step time (sham, $339 \pm 23.5 \mathrm{~ms}$; experimental animals, $358 \pm 29 \mathrm{~ms}$ ) but significant differences in stepping pattern (Fig. 6H-J). Whereas both groups showed increasing familiarity with the ladder as reflected in a significant increase in long steps (Fig. $6 H, p<0.0001$ ) and a reduction in backsteps (Fig. 6I, $p<0.0001$ ) over trial days, the experimental group jumped significantly fewer times than the sham group (Fig. 6J; two-way ANOVA, $p=$ $\left.0.0033, F_{(1,80)}=9.20\right)$. This suggests a reduced competence in motor function, matching the initially higher misstep rate in this group (Fig. 6F).

After the $4 \mathrm{~d}$ of training on the ladder, the mice were then tested over subsequent days 5-8 with a conditioned learning paradigm. The instantaneous introduction of an obstacle rung, which disturbs the stepping pattern (Fig. $6 G$ ), was used as an unconditioned stimulus. A $90 \mathrm{~dB}, 2 \mathrm{kHz}$ tone lasting $250 \mathrm{~ms}$ was used as a conditional stimulus $250 \mathrm{~ms}$ before the introduction of the obstacle. The length of time needed to overcome the obstacle (postperturbation step time) was measured. On trial days, each mouse was given unperturbed trials, paired trials, or conditioned stimulusonly trials or unconditioned stimulusonly trials as summarized in Figure $6 \mathrm{~K}$. Postperturbation step times are similar to the average step times on days $1-4$. When the obstacle is first introduced on day 5 , mice in both the experimental and sham groups show a significant increase in postperturbation step time. This reduces over the course of $4 \mathrm{~d}$ of successive trials for 
A

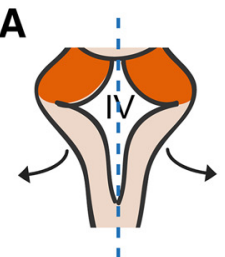

B

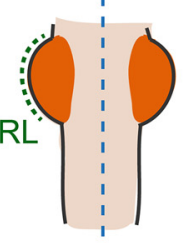

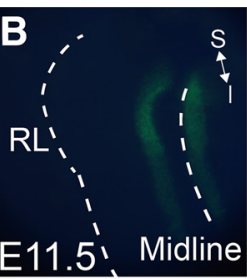

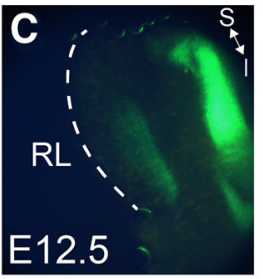

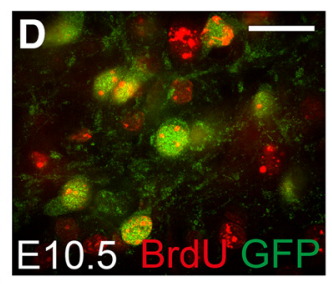

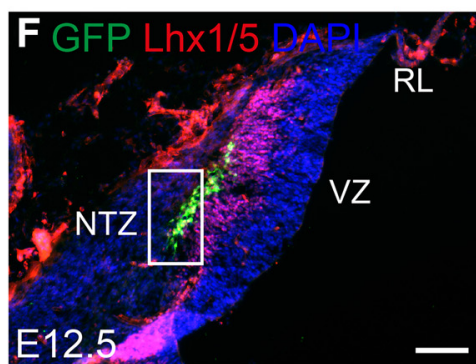

Sox14 ${ }^{\mathrm{Gfp} /+}$

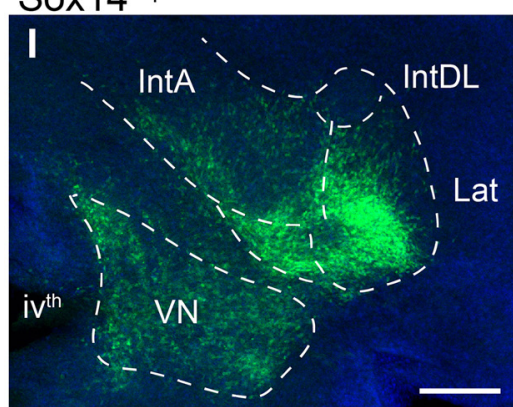

Sox $14^{+/+}$

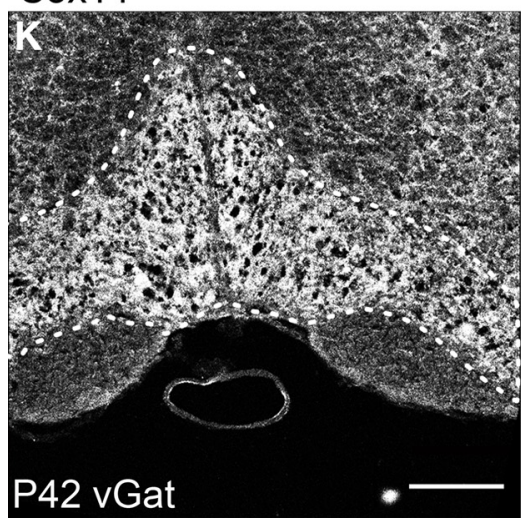

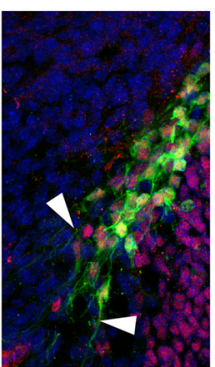

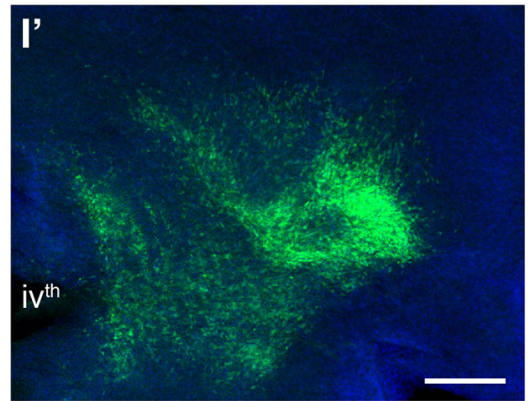

Sox $14^{\mathrm{Gfp} / \mathrm{Gfp}}$

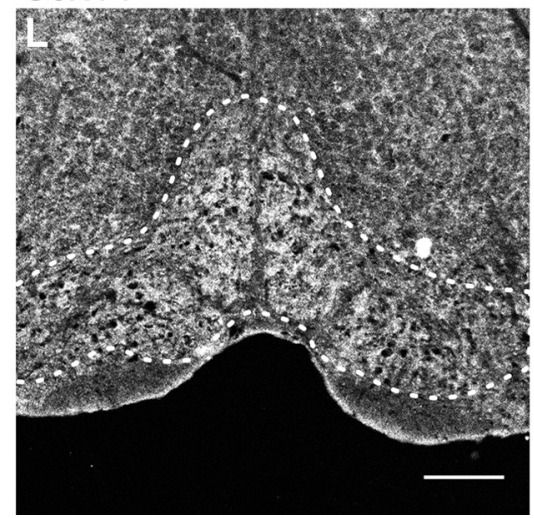

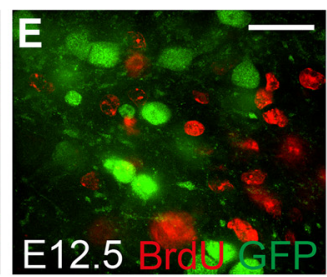

$\mathbf{H}$

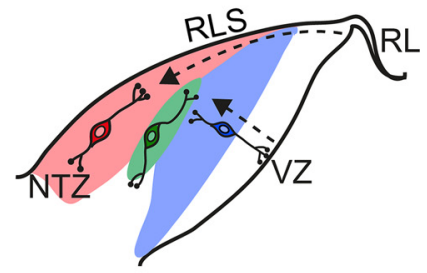

Sox14Gfp/Gfp

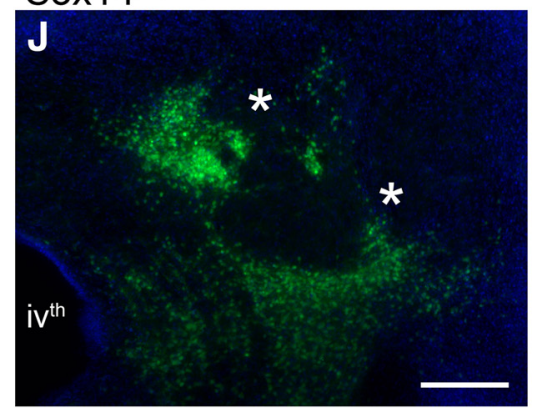

M

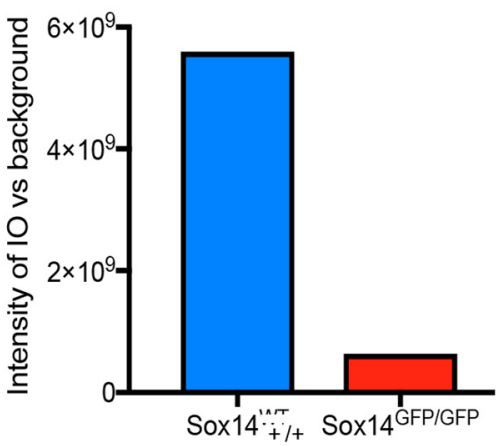

Figure 5. Integration of inhibitory projection neurons into the nuclei is mediated by Sox 14 . A, Sox $14^{\mathrm{Gfp} /+}$ hindbrains were opened up dorsally along the midline and mounted flat so that the rhombic lip, which originally lined the intersection between the cerebellum and roof plate, is the most lateral edge (in green); the cerebellar anlage is in orange. $\boldsymbol{B}$, $\boldsymbol{C}$, GFP expression is seen at E11.5 $(\boldsymbol{B})$ and E12.5 $(\boldsymbol{C})$ on either side of the midline, whereas expression in the cerebellar plate is only seen from E12.5 onward. $\boldsymbol{D}, \boldsymbol{E}, \mathrm{BrdU}$ birth-dating analysis. Scale bars, $20 \mu \mathrm{m}$. GFP ${ }^{+}$cells colocalize with BrdU that was injected at E10.5 (D), whereas BrdU injected at E12.5 (E) shows no colocalization, indicating that all the GFP ${ }^{+}$cells are born before E12.5. $\boldsymbol{F}$, In situ hybridization against Lhx $1 / 5$ and GFP in the Sox $14{ }^{\mathrm{Gfp} /+}$ E12.5 sagittal brain sections. The Lhx $1 / 5$-expressing cells span the anteroposterior axis of the cortical transitory zone and are mostly Purkinje cell precursors. However, there is a dorsal layer of the $\mathrm{Lhx} 1 / 5^{+}$and GFP ${ }^{+}$population that are genetically distinct, as shown in the higher-magnification image (inset). These cells appear to be in a tangential orientation (white arrowheads), unlike the GFP ${ }^{-} /$Lhx $1 / 5^{+}$Purkinje cells that are migrating radially from the ventricular zone. $\boldsymbol{G}$, $\mathrm{Pax}^{+}{ }^{+}$cells migrating along the rhombic lip migratory stream toward the nuclear transitory zone sit dorsal to the GFP ${ }^{+}$cells. $\boldsymbol{H}$, A schematic to show the tangential orientation of the $\mathrm{GFP}^{+}$cells (green) alongside the Pax6 excitatory cells migrating tangentially along the subpial rhombic lip migratory stream (RLS, red) and the GFP ${ }^{-} /$Lhx $/ 5^{+}$Purkinje cells that are migrating radially from the ventricular zone. $I, J$, Coronal sections of the Sox $14^{+}$cells in the developing CN of PO Sox $14^{\text {Gfp/+ }}$ mouse $(I)$ compared with the Sox $14{ }^{\text {Gfp/Gfp }}$ knock-out mouse (J). Scale bars, $200 \mu \mathrm{m} . I^{\prime}$, The same image without borders drawn to highlight that for the Sox $14^{\mathrm{Gfp} /+}$ mouse, the migratory streams already resemble the future boundaries between the subnuclei, whereas for the knock-out, the cells fail to populate some areas, leaving large gaps (asterisks) and deviant clusters of cells. There are still some likenesses between the two brains, which suggest that there are other migratory mechanisms at work in the development of nucleo-olivary neurons. $\boldsymbol{K}-\boldsymbol{M}$, Density of vGAT labeling in the inferior olive of an adult wild-type $(\boldsymbol{K})$ and Sox14 mutant $(\boldsymbol{L})$ mouse shows a difference in signal to background intensity $(\boldsymbol{M})$. Scale bars: $\boldsymbol{F}, 100 \mu \mathrm{m} ; \boldsymbol{I}-\boldsymbol{L}, 200 \mu \mathrm{m}$. RL, Rhombic lip; Lat, lateral nucleus; IntDL, dorsolateral interposed nucleus; IntA, anterior interposed nucleus; VN, vestibular nucleus; VZ, ventricular zone; ivth, fourth ventricle.

both paired and unconditioned stimulus-only trials. Therefore, in contrast to rotarod experiments, both groups of animals showed an equivalent improvement in ability (reduced postperturbation step time) to bypass an instantaneously raised rung. When the obstacle is preceded by an auditory cue, mice in both groups show a significantly more rapid habituation to the obstacle and postperturbation step times are shorter, indicating an ability to predict the imminent obstacle. Learning in both the experimental 
A

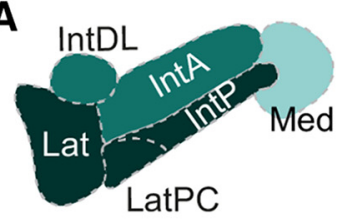

Sham injected

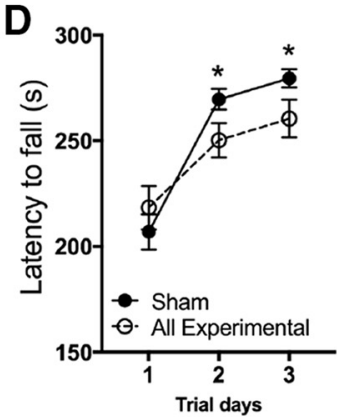

G

Obstacle rung

Higher rung

Lower rung
B

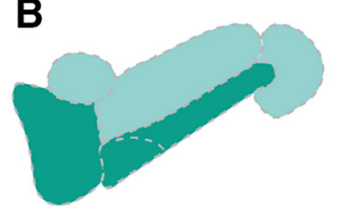

All Experimental

E

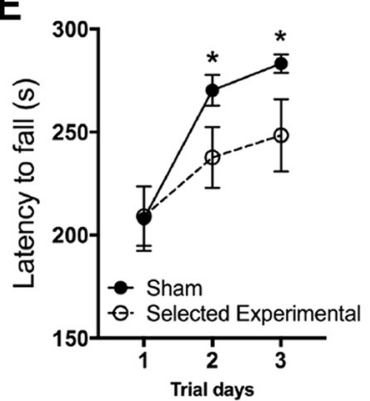

C

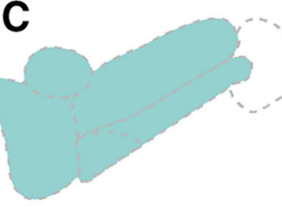

Selected Experimental

F

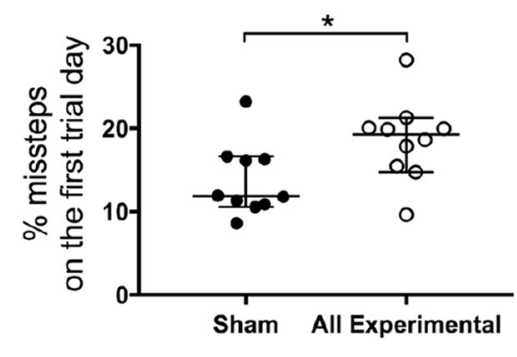

Average Density

of Gad1 cells

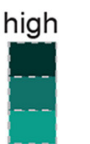

low

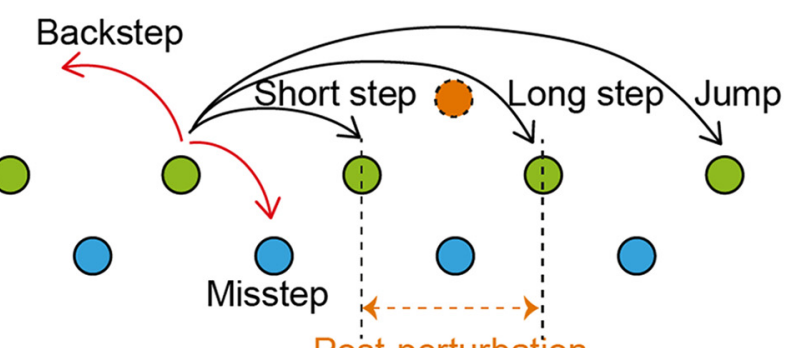

Post-perturbation

step time
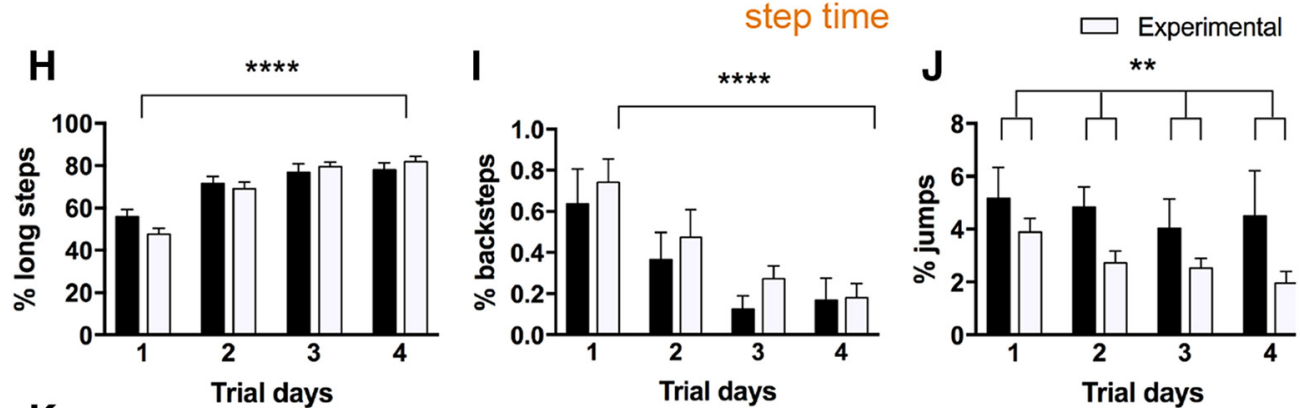

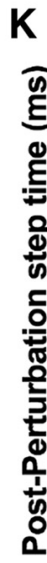

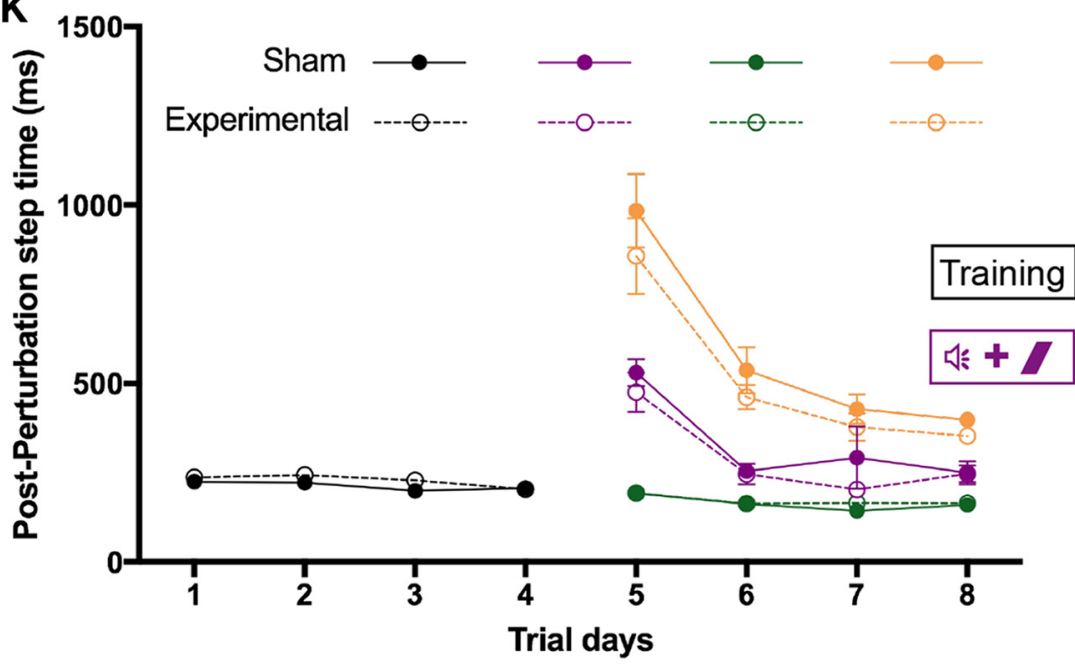

Figure 6. Targeted ablation of Sox 14 neurons leads to locomotor dysfunction. Assessment using Gad 1 labeling as a measure of nucleo-olivary cell loss is shown. $\boldsymbol{A}-\boldsymbol{C}$, The schematic represents the average density of Gad1-reactive cells in the sham-injected mice $(\boldsymbol{A})$, all the Sox $14{ }^{\mathrm{Cre} /+}$ experimental mice $(\boldsymbol{B})$, and selected averaged data for the six experimental mice that showed extensive cell loss $(>70 \%)$ compared with sham (C). D, Rotarod data for all experimental mice against the sham-injected group. The experimental mice show significantly reduced latencies for both day 2 $(p=0.0324)$ and day3 $(p=0.0374)$. $\boldsymbol{E}$, Rotarod data for the six selected experimental mice shown in $\mathbf{C}$ against the sham-injected group. The selected group (Figure legend continues.) 
and sham groups was not significantly different for any of the trial types. Therefore, both groups show an equal associative learning through the introduction of a conditional cue before the introduction of an obstacle.

\section{Discussion}

In this study, we show that Sox14 defines at least two molecularly distinct populations of GABAergic projection neurons in the lateral and interposed nucleus that project both contralaterally and ipsilaterally to the inferior olive. A small population of Sox $14^{+}$ neurons in nucleus $\mathrm{Y}$ of the vestibular nucleus projects to the ipsilateral oculomotor nucleus. Ablation of the interposed nucleus population leads to defects in motor function and motor learning, but not to any deficit in associative motor learning.

\section{Sox14 is a genetic marker for nucleo-olivary neurons in the lateral and interposed nuclei}

Within the lateral and interposed nucleus, our results show that Sox14 is expressed exclusively in GABAergic projection neurons that target the inferior olive. Our axonal mapping data concurs with previous tracer studies that have shown both the location of projection neurons within nuclei and the orderly topographic projection of each nucleus to the different olivary subnuclei (Tolbert et al., 1976; Brown et al., 1977; Buisseret-Delmas and Batini, 1978; Legendre and Courville, 1987; Giaquinta et al., 1999). We also identify Sox14 neurons in nucleus Y that account for the previously characterized ipsilateral projection from this region to the oculomotor nucleus (Graybiel and Hartwieg, 1974; Steiger and Büttner-Ennever, 1979; Stanton, 1980; Yamamoto et al.,

$\leftarrow$

(Figure legend continued.) performed worse with significantly reduced latencies for both day $2(p=0.041)$ and day $3(p=0.036)$. Mean \pm SEM; two-way ANOVA followed by Bonferroni's post-tests: main effect of trial time, $F_{(2,120)}=1122, p<0.0001$; main effect of ablation, $F_{(1,120)}=4.479, p=0.0064$; ablation $\times$ trial time interaction, $F_{(2,1.20)}=1.25, p=0.2903 . F$, Percentage of missteps measured on the introduction onto the Erasmus ladder apparatus shows the experimental group initially made more mistakes compared with the sham group. The median percentage of missteps in the sham and experimental groups was 11.85 and $19.26 \%$, respectively; thus the distributions in the two groups differed significantly (Mann-Whitney $U$ test, $23 ; n_{1}=10, n_{2}=10, p=0.0433$, two-tailed; median with $95 \%$ (l). $\mathbf{G}$, The various types of steps that are measured (image adapted from Noldus). The mouse ordinarily prefers to travel along the top set of rungs (green) and can perform short, long, or jump steps according to how many rungs are skipped between steps. The mouse may also take back steps, moving backward against the tailwind, or perform a misstep, where a mistake leads the mouse to step onto a lower set of rungs (blue). During associative learning trials, an obstacle rung (orange) may swing up to obstruct the path of the mouse so that it must step over the rung. Although the placement of the obstacle rung may change between trials, the postperturbation step time is defined as the time between activation of the rung before the obstacle to the rung after the obstacle. $\boldsymbol{H}-\boldsymbol{J}$, Usage of various step types over the training days (days $1-4)$. $\boldsymbol{H}$, The percentage of steps that were long steps used in each trial day. The effect of trial days was extremely significant $\left(p<0.0001, F_{(3,80)}=36.32\right)$. I, The percentage of steps that were backsteps used in each trial day. The effect of trial days was extremely significant $\left(p<0.0001, F_{(3,80)}=9.27\right)$. $\boldsymbol{J}$, The percentage of steps that were jumps used in each trial day. The effect of ablative injection was significant, showing a decreased percentage of jumps in the experimental animals compared with sham (adjusted $p=0.0033, F_{(1,80)}=9.20$, two-way ANOVA corrected method of Benjamini and Yekutieli, mean \pm SEM). $K$, Postperturbation step times in the different associative learning trials. During the first $4 \mathrm{~d}$, only undisturbed trials were run to train the mice to traverse the ladder. Since there is no obstacle in these trials, the postperturbation step time is the average step time for a normal step (black). 0 n days $5-8$, trials are run so that the mouse is presented with either (S-only (green), US-only (orange), or paired CS-US (purple) stimuli. Where there is an obstacle presented in the trial, the postperturbation step time will increase if the mouse is not anticipating the obstacle. In all trial types, there was no significant difference in postperturbation step time between the two groups (mean \pm SEM). US, Unconditioned stimulus; CS, conditioned stimulus; Lat, Lateral nucleus; LatPC, parvicellular lateral nucleus; IntDL, dorsolateral interposed nucleus; Int $A$, anterior interposed nucleus; Med, medial nucleus; IntP, posterior interposed nucleus. ${ }^{*} p<0.05$; ${ }^{* *} p<0.01$; ${ }^{* * *} p<0.0001$.
1986). Because of the modular nature of the nucleo-olivary circuit, it is possible to speculate that Sox 14 neurons would broadly have a role in higher cognition, motor planning (lateral nucleus), visuomotor control (ventromedial lateral nucleus), and associative learning (interposed nucleus). The nucleus Y projection is involved in the regulation of the vertical vestibulo-ocular reflex (Chubb and Fuchs, 1982; Highstein et al., 1997). The significance of a subpopulation of Calretinin-positive, Sox14-positive projection neurons is unclear. In the lateral nucleus, Sox14 expression in the ventromedial, parvicellular lateral nucleus maps to the location of inferior olive projection neurons identified in previous mapping experiments and hence to the bulk of the Calretinin population. This cluster is not associated with the laterality of projection: by contrast, ipsilaterally and contralaterally projecting neurons are evenly distributed across the nuclei. Sox14 neurons account for the majority, but not all, of the GABAergic neurons in the lateral and interposed nuclei. The Sox14-negative inhibitory fraction comprises both local interneurons and projection neurons that send inhibitory connections to the cerebellar cortex (Uusisaari and Knöpfel, 2011; Houck and Person, 2014). This difference is visualized in the Allen Mouse Brain Connectivity Atlas Projection data using the Slc32a1-IRES-Cre mouse, where Slc32al is expressed in all inhibitory cell types; Credependent AAV injections reveal additional projections from the cerebellar nuclei to the cerebellar cortex that are not seen using the Sox14-Cre mouse. Cell-body size distribution does not distinguish these different groups. All are relatively small compared with the parvalbumin-positive (presumably glutamatergic projection) neurons that have a roughly complementary distribution within the nuclei.

\section{Olivary projection neurons are a distinct early born cohort of GABAergic derivatives}

Our data reveal a striking absence of Sox 14 neurons in the medial nucleus, suggesting that its descending inhibitory projection has distinct embryonic origins. The medial nucleus displays a unique GABAergic marker, Zac1 (Chung et al., 2011), and the descending olivary projection from the medial nucleus projects along its own distinct tract (Dom et al., 1973; Martin et al., 1976; Legendre and Courville, 1987). This may correspond to its presumed phylogentically more ancient origin (Green and Wingate, 2014) linked to reflex motor functions such as the vestibulo-ocular reflexes, optokinetic control, and saccades (Ito, 2013). Ito (2013) also argues that the medial olivo-cerebellar module is distinct in its capacity to drive motor patterns in contrast to the more modulatory function of other nuclei. The medial is also the only nucleus to contain large glycinergic neurons, which project to vestibular and reticular hindbrain targets (Bagnall et al., 2009; Chung et al., 2009).

Developmentally, both $L h x 1 / 5$-positive Sox14 neurons and Zac1-positive cells (Chung et al., 2011) lie adjacent to the NTZ where rhombic lip-derived glutamatergic nuclear cells assemble at E12-E13. All GABAergic cerebellar neurons are derived from precursors that express Ptfla (Hoshino et al., 2005). The birth date of Sox14 cerebellar neurons (E10.5) also corresponds to a transient early expression of $A s c l 1$ in the ventricular zone (Kim et al., 2008) and Neurog2 (Zordan et al., 2008), suggesting that, as in the diencephalon, Sox14 neurons transiently express Ascl1 (Delogu et al., 2012). GABAergic nuclear neurons produced during a later wave of Ascl1 expression in Ptfla precursors (E13-E16) likely correspond to local interneurons that are also characterized by Neurog1 (Lundell et al., 2009) and Pax2 (Maricich and Herrup, 1999) expression. Our results suggest that the early wave of 
GABAergic cell production in Ascl1/Ptfla progenitors exclusively generates projection neurons and is remarkably synchronized to the production of glutamatergic neurons from the rhombic lip, as well as to the production of olivary cells that send up climbing fibers (Pierce, 1973; Hoshino, 2012). Like rhombic lip derivatives, Sox14 neurons are tangentially orientated at the NTZ, suggesting some capacity for nonradial migration. Sox 14 itself appears to be required for the successful integration of populations into a nucleus; however, we cannot determine whether Sox14 is required for an olivary axon projection, particularly since the medial nucleus GABAergic nuclear projection is Sox 14 independent. When Sox 14 is deleted, we find that cells are unable to migrate into their normal location, reminiscent of its role in facilitating migration in the formation of an integrated excitatory and inhibitory dorsal thalamus (Delogu et al., 2012; Jager et al., 2016).

\section{The role of the nucleo-olivary projection in motor function and learning}

We used a bilateral, conditional viral-mediated ablation protocol to test the function of Sox 14 neurons and revealed a significant deficit in motor coordination (missteps on walking a ladder), which improved with experience, and impaired learning on a balance test (rotarod). In contrast to expectations (Medina et al., 2002), there was no impairment to associative learning where both experimental and control groups showed a positive response to priming an obstacle task with a conditioned auditory stimulus.

Viral injections produce varying degrees of cell loss within the cerebellar nuclei, and it is possible that a more complete ablation might have led to stronger learning defects. Similarly, for associative learning, a range of approaches (including eye-blink conditioning and investigations into extinction, reacquisition, and blocking of conditioned responses) might show functions of the nucleo-olivary feedback that were not tested in the present study. Nevertheless, our study represents the first selective experimental ablation of nucleo-olivary projection neurons, and implications of our observations are that either cerebello-olivary inputs are not involved in nonassociative learning rather than associative learning or that they are partially redundant to other GABAergic inputs to the olive (Geborek et al., 2012). There is strong evidence that activity in descending inhibitory axons decreases the extent of coupling between inferior olivary neurons (Lefler et al., 2014) and, by implication, the synchronous activity of Purkinje cells, which they in turn excite. Our results are consistent with coupling playing a role in the fine-tuning of motor learning (Schweighofer et al., 2013). We find that learning is not abolished but significantly less efficient after ablation of Sox14 neurons.

Our results contrast with the consequences of constitutively reduced electrotonic coupling in the inferior olive in the Cx36 knock-out mouse (Van Der Giessen et al., 2008). In the latter model, although a similar impairment of basic motor function is revealed on the Erasmus ladder test, there is a non-accompanying significant deficit in associative learning. A parsimonious explanation is that conditioning in this task relies on bilateral brain function and that intact unilateral pathways from incomplete ablation are sufficient to mask any deficit. Similarly, sprouting of axons to the damaged nuclei from the contralateral, intact olive (Sugihara et al., 2003; Dixon et al., 2005) or regulation within olivary neurons themselves (Long et al., 2002; De Zeeuw et al., 2003) may provide a developmental compensation for aberrant function. More intriguing is that our results may indicate that the nucleoolivary input is not the sole regulator of gap junction coupling in the inferior olive, pointing to a role for other pathways in modulating cerebello-olivary feedback (Geborek et al., 2012).

\section{Conclusion}

In summary, we show that Sox14 exclusively identifies GABAergic nucleo-olivary projection neurons of the interposed and lateral nuclei. The medial cerebellar nucleus has an anatomically and genetically distinct olivary projection. Sox14-positive cells appear to be the earliest born cohort of GABAergic neurons, generated contemporaneously with glutamatergic nuclear neurons at the rhombic lip, which coassemble at the NTZ and integrate as a series of nuclei in a Sox14-dependent mechanism. Finally, targeted partial ablation of Sox $14^{+}$cells in the cerebellar nuclei leads to significant deficits in motor learning, but not to an impaired associative learning.

\section{References}

Aizenman CD, Huang EJ, Linden DJ (2003) Morphological correlates of intrinsic electrical excitability in neurons of the deep cerebellar nuclei. J Neurophysiol 89:1738-1747. CrossRef Medline

Altman J, Bayer SA (1985) Embryonic development of the rat cerebellum. II. Translocation and regional distribution of the deep neurons. J Comp Neurol 231:27-41. CrossRef Medline

Bagnall MW, Zingg B, Sakatos A, Moghadam SH, Zeilhofer HU, du Lac S (2009) Glycinergic projection neurons of the cerebellum. J Neurosci 29: 10104-10110. CrossRef Medline

Bengtsson F, Svensson P, Hesslow G (2004) Feedback control of Purkinje cell activity by the cerebello-olivary pathway. Eur J Neurosci 20:29993005. CrossRef Medline

Bengtsson F, Jirenhed DA, Svensson P, Hesslow G (2007) Extinction of conditioned blink responses by cerebello-olivary pathway stimulation. Neuroreport 18:1479-1482. CrossRef Medline

Best AR, Regehr WG (2009) Inhibitory regulation of electrically coupled neurons in the inferior olive is mediated by asynchronous release of GABA. Neuron 62:555-565. CrossRef Medline

Brown JT, Chan-Palay V, Palay SL (1977) A study of afferent input to the inferior olivary complex in the rat by retrograde axonal transport of horseradish peroxidase. J Comp Neurol 176:1-22. CrossRef Medline

Buisseret-Delmas C, Batini C (1978) Topology of the pathways to the inferior olive as? study in cat. Neurosci Lett 10:207-214. CrossRef Medline

Cerminara NL, Apps R (2011) Behavioural significance of cerebellar modules. Cerebellum 10:484-494. CrossRef Medline

Chan-Palay V (1977) Cerebellar dentate nucleus: organization, cytology and transmitters. Berlin: Springer.

Chubb MC, Fuchs AF (1982) Contribution of y group of vestibular nuclei and dentate nucleus of cerebellum to generation of vertical smooth eye movements. J Neurophysiol 48:75-99. CrossRef Medline

Chung SH, Marzban H, Hawkes R (2009) Compartmentation of the cerebellar nuclei of the mouse. Neuroscience 161:123-138. CrossRef Medline

Chung SH, Marzban H, Aldinger K, Dixit R, Millen K, Schuurmans C, Hawkes R (2011) Zacl plays a key role in the development of specific neuronal subsets in the mouse cerebellum. Neural Dev 6:25. CrossRef Medline

Delogu A, Sellers K, Zagoraiou L, Bocianowska-Zbrog A, Mandal S, Guimera J, Rubenstein JL, Sugden D, Jessell T, Lumsden A (2012) Subcortical visual shell nuclei targeted by ipRGCs develop from a Sox14+GABAergic progenitor and require Sox14 to regulate daily activity rhythms. Neuron 75:648-662. CrossRef Medline

De Zeeuw CI, Chorev E, Devor A, Manor Y, Van Der Giessen RS, De Jeu MT, Hoogenraad CC, Bijman J, Ruigrok TJ, French P, Jaarsma D, Kistler WM, Meier C, Petrasch-Parwez E, Dermietzel R, Sohl G, Gueldenagel M, Willecke K, Yarom Y (2003) Deformation of network connectivity in the inferior olive of connexin 36-deficient mice is compensated by morphological and electrophysiological changes at the single neuron level. J Neurosci 23:4700-4711. CrossRef Medline

Dixon KJ, Hilber W, Speare S, Willson ML, Bower AJ, Sherrard RM (2005) Post-lesion transcommissural olivocerebellar reinnervation improves motor function following unilateral pedunculotomy in the neonatal rat. Exp Neurol 196:254-265. CrossRef Medline

Dom R, King S, Martin GF (1973) Evidence for two direct cerebello-olivary connections. Brain Res 57:498-501. CrossRef Medline

Fink AJ, Englund C, Daza RA, Pham D, Lau C, Nivison M, Kowalczyk T, Hevner RF (2006) Development of the deep cerebellar nuclei: transcription factors and cell migration from the rhombic lip. J Neurosci 26:30663076. CrossRef Medline 
Geborek P, JörntellH, Bengtsson F (2012) Stimulation within the cuneate nucleus suppresses synaptic activation of climbing fibers. Front Neural Circuits 6:120. Medline

Giaquinta G, Casabona A, Smecca G, Bosco G, Perciavalle V (1999) Cortical control of cerebellar dentato-rubral and dentato-olivary neurons. Neuroreport 10:3009-3013. CrossRef Medline

Gilthorpe JD, Papantoniou EK, ChédotalA, Lumsden A, Wingate RJ (2002) The migration of cerebellar rhombic lip derivatives. Development 129: 4719-4728. Medline

Graybiel AM, Hartwieg EA (1974) Some afferent connections of the oculomotor complex in the cat: an experimental study with tracer techniques. Brain Res 81:543-551. CrossRef Medline

Green MJ, Wingate RJ (2014) Developmental origins of diversity in cerebellar output nuclei. Neural Dev 9:1. CrossRef Medline

Hargrave M, Karunaratne A, Cox L, Wood S, Koopman P, Yamada T (2000) The HMG box transcription factor gene Sox14 marks a novel subset of ventral interneurons and is regulated by sonic hedgehog. Dev Biol 219: 142-153. CrossRef Medline

Hesslow G, Ivarsson M (1996) Inhibition of the inferior olive during conditioned responses in the decerebrate ferret. Exp Brain Res 110:36-46. Medline

Highstein SM, Partsalis A, Arikan R (1997) Role of the Y-group of the vestibular nuclei and flocculus of the cerebellum in motor learning of the vertical vestibulo-ocular reflex. Prog Brain Res 114:383-397. CrossRef Medline

Hoshino M (2012) Neuronal subtype specification in the cerebellum and dorsal hindbrain. Dev Growth Differ 54:317-326. CrossRef Medline

Hoshino M, Nakamura S, Mori K, Kawauchi T, Terao M, Nishimura YV, Fukuda A, Fuse T, Matsuo N, Sone M, Watanabe M, Bito H, Terashima T, Wright CV, Kawaguchi Y, Nakao K, Nabeshima Y (2005) Ptfla, a bHLH transcriptional gene, defines GABAergic neuronal fates in cerebellum. Neuron 47:201-213. CrossRef Medline

Houck BD, Person AL (2014) Cerebellar loops: a review of the nucleocortical pathway. Cerebellum 13:378-385. CrossRef Medline

Ito M (2013) Error detection and representation in the olivo-cerebellar system. Front Neural Circuits 7:1. Medline

Jager P, Ye Z, Yu X, Zagoraiou L, Prekop HT, Partanen J, Jessell TM, Wisden W, Brickley SG, Delogu A (2016) Tectal-derived interneurons contribute to phasic and tonic inhibition in the visual thalamus. Nat Commun 7:13579. CrossRef Medline

Kim EJ, Battiste J, Nakagawa Y, Johnson JE (2008) Ascl1 (Mash1) lineage cells contribute to discrete cell populations in CNS architecture. Mol Cell Neurosci 38:595-606. CrossRef Medline

Kistler WM, De Jeu MT, Elgersma Y, Van Der Giessen RS, Hensbroek R, Luo C, Koekkoek SK, Hoogenraad CC, Hamers FP, Gueldenagel M, Sohl G, Willecke K, De Zeeuw CI (2002) Analysis of Cx36 knockout does not support tenet that olivary gap junctions are required for complex spike synchronization and normal motor performance. Ann N Y Acad Sci 978: 391-404. CrossRef Medline

Lang EJ, Sugihara I, Llinás R (1996) GABAergic modulation of complex spike activity by the cerebellar nucleoolivary pathway in rat. J Neurophysiol 76:255-275. CrossRef Medline

Lefler Y, Yarom Y, Uusisaari MY (2014) Cerebellar inhibitory input to the inferior olive decreases electrical coupling and blocks subthreshold oscillations. Neuron 81:1389-1400. CrossRef Medline

Legendre A, Courville J (1987) Origin and trajectory of the cerebello-olivary projection: an experimental study with radioactive and fluorescent tracers in the cat. Neuroscience 21:877-891. CrossRef Medline

Leznik E, Makarenko V, Llinás R (2002) Electrotonically mediated oscillatory patterns in neuronal ensembles: an in vitro voltage-dependent dye-imaging study in the inferior olive. J Neurosci 22:2804-2815. CrossRef Medline

Llinás RR (2011) Cerebellar motor learning versus cerebellar motor timing: the climbing fibre story. J Physiol 589:3423-3432. CrossRef Medline

Llinás RR (2013) The olivo-cerebellar system: a key to understanding the functional significance of intrinsic oscillatory brain properties. Front Neural Circuits 7:96. Medline

Long MA, Deans MR, Paul DL, Connors BW (2002) Rhythmicity without synchrony in the electrically uncoupled inferior olive. J Neurosci 22: 10898-10905. CrossRef Medline

Lundell TG, Zhou Q, Doughty ML (2009) Neurogenin1 expression in cell lineages of the cerebellar cortex in embryonic and postnatal mice. Dev Dyn 238:3310-3325. CrossRef Medline
Machold R, Fishell G (2005) Math1 is expressed in temporally discrete pools of cerebellar rhombic-lip neural progenitors. Neuron 48:17-24. CrossRef Medline

Maricich SM, Herrup K (1999) Pax-2 expression defines a subset of GABAergic interneurons and their precursors in the developing murine cerebellum. J Neurobiol 41:281-294. CrossRef Medline

Martin GF, Henkel CK, King JS (1976) Cerebello-olivary fibers: their origin, course and distribution in the North American opossum. Exp Brain Res 24:219-236. Medline

McClellan KM, Parker KL, Tobet S (2006) Development of the ventromedial nucleus of the hypothalamus. Front Neuroendocrinol 27:193-209. CrossRef Medline

Medina JF, Nores WL, Mauk MD (2002) Inhibition of climbing fibres is a signal for the extinction of conditioned eyelid responses. Nature 416:330 333. CrossRef Medline

Morales D, Hatten ME (2006) Molecular markers of neuronal progenitors in the embryonic cerebellar anlage. J Neurosci 26:12226-12236. CrossRef Medline

Myat A, Henrique D, Ish-Horowicz D, Lewis J (1996) A chick homologue of serrate and its relationship with notch and delta homologues during central neurogenesis. Dev Biol 174:233-247. CrossRef Medline

Najac M, Raman IM (2015) Integration of Purkinje cell inhibition by cerebellar nucleo-olivary neurons. J Neurosci 35:544-549. CrossRef Medline

Pierce ET (1973) Time of Origin of Neurons in the Brain Stem of the Mouse. In: Progress in Brain Research, Vol 40 (Ford DH, ed), pp. 53-65. Amsterdam: Elsevier.

Schweighofer N, Lang EJ, Kawato M (2013) Role of the olivo-cerebellar complex in motor learning and control. Front Neural Circuits 7:94. Medline

Sears LL, Steinmetz JE (1991) Dorsal accessory inferior olive activity diminishes during acquisition of the rabbit classically conditioned eyelid response. Brain Res 545:114-122. CrossRef Medline

Stanton GB (1980) Afferents to oculomotor nuclei from area "Y" in Macaca mulatta: an anterograde degeneration study. J Comp Neurol 192:377_ 385. CrossRef Medline

Steiger HJ, Büttner-Ennever JA (1979) Oculomotor nucleus afferents in the monkey demonstrated with horseradish peroxidase. Brain Res 160:1-15. CrossRef Medline

Sugihara I, Lohof AM, Letellier M, Mariani J, Sherrard RM (2003) Post-lesion transcommissural growth of olivary climbing fibres creates functional synaptic microzones. Eur J Neurosci 18:3027-3036. CrossRef Medline

Tolbert DL, Massopust LC, Murphy MG, Young PA (1976) The anatomical organization of the cerebello-olivary projection in the cat. J Comp Neurol 170:525-544. CrossRef Medline

Uusisaari M, Knöpfel T (2011) Functional classification of neurons in the mouse lateral cerebellar nuclei. Cerebellum 10:637-646. CrossRef Medline

Uusisaari M, Obata K, Knöpfel T (2007) Morphological and electrophysiological properties of GABAergic and non-GABAergic cells in the deep cerebellar nuclei. J Neurophysiol 97:901-911. CrossRef Medline

Uusisaari MY, KnöpfelT (2012) Diversity of neuronal elements and circuitry in the cerebellar nuclei. Cerebellum 11:420-421. CrossRef Medline

Van Der Giessen RS, Koekkoek SK, van Dorp S, De Gruijl JR, Cupido A, Khosrovani S, Dortland B, Wellershaus K, Degen J, Deuchars J, Fuchs EC, Monyer H, Willecke K, De Jeu MT, De Zeeuw CI (2008) Role of olivary electrical coupling in cerebellar motor learning. Neuron 58:599-612. CrossRef Medline

Vinueza Veloz MF, Zhou K, Bosman LW, Potters JW, Negrello M, Seepers RM, Strydis C, Koekkoek SK, De Zeeuw CI (2015) Cerebellar control of gait and interlimb coordination. Brain Struct Funct 220:3513-3536. CrossRef Medline

Wang VY, Rose MF, Zoghbi HY (2005) Math1 expression redefines the rhombic lip derivatives and reveals novel lineages within the brainstem and cerebellum. Neuron 48:31-43. CrossRef Medline

Yamamoto F, Sato Y, Kawasaki T (1986) The neuronal pathway from the flocculus to the oculomotor nucleus: an electrophysiological study of group y nucleus in cats. Brain Res 371:350-354. CrossRef Medline

Zordan P, Croci L, Hawkes R, Consalez GG (2008) Comparative analysis of proneural gene expression in the embryonic cerebellum. Dev Dyn 237: 1726-1735. CrossRef Medline 